\title{
Harf Çizgilerini Çizme Yönü ile Çizme Hızı ve Çizgi Niteliği Arasındaki İlişki
}

\author{
Mustafa BAŞARAN*
}

• Geliş Tarihi: 31.01.2020 • Kabul Tarihi: 27.10.2020 • Yayın Tarihi: 27.10.2020

\section{$\ddot{\mathbf{O} z}$}

Harf çizgilerini çizme yönü ile çizme hızı ve çizgilerin niteliği arasındaki ilişkinin tespiti amacıyla yapılan bu araştırmada karma yöntem kullanılmıştır. Araştırmanın çalışma evrenini İstanbul ili Esenler ve Zeytinburnu ilçelerinde bulunan devlet ilkokullarında öğrenimlerine devam eden 1, 2, 3 ve 4. sınıf öğrencileri oluşturmaktadır. Bu evrenden amaçlı örnekleme tekniklerinden ölçüt örnekleme kullanılarak seçilen 41'i 1., 39’u 2., 40’1 3. ve 44'ü 4. sınıf olmak üzere toplam 164 öğrenci çalışma grubu olarak belirlenmiştir. Araştırma sonuçlarına göre 1, 2, 3 ve 4. sınıf düzeyinde dik, eğik, yatay çizgiler ile daire çizmede çizgi çekim yönünün çizginin çekim süresi üzerinde anlamlı bir etkisi bulunmadığı ancak betimsel verilere göre tüm sınıf seviyelerinde dik, sağa ve sola eğik çizgilerin yukarıdan aşağıya; yatay çizgilerin ise soldan sağa daha hızlı çekildiği görülmüştür. Dairenin çizim yönünün dairenin çizim süresi üzerindeki etkisi çok az olmakta ve daire diğer çizgilere göre daha hızlı çizilmektedir. Çizgilerin çekim yönü, çizgi çizme hızına göre, çizgilerin niteliği üzerinde daha etkili olmaktadır. Öğrenciler dik ve eğik harf çizgilerini yukarıdan aşağıya; yatay çizgileri soldan sağa ve daireyi de saat yönünün tersine çizdiklerinde çizgi nitelikleri artmaktadır.

Anahtar kelimeler: Harf çizgileri, harf çizgileri çekim yönü, yazma hızı, harf çizgilerinin niteliği

Atıf:

Başaran, M. (2021). Harf çizgilerini çizme yönü ile çizme hızı ve çizgi niteliği arasındaki ilişki.

Pamukkale Üniversitesi Ĕ̈itim Fakültesi Dergisi, 52, 86-118. doi:10.9779.pauefd.682929

\footnotetext{
* Doç. Dr., Yıldız Teknik Üniversitesi, Eğitim Fakültesi, Temel Eğitim Böl. e-posta: mbasaran66@yahoo.com ORCID ID: 0000-0003-1684-5852
} 


\section{Giriş}

Dil öğretiminin amacı bireylere okuma, yazma, dinleme ve konuşma olarak sıralanabilecek dil becerilerini kazandırmaktır. Bu beceriler içerisinde medeniyetin oluşturulması ve sonraki nesle aktarılmasında en önemli becerinin "yazma” olduğu söylenebilir. Çünkü yazı, üretilen bilgiyi kalıcı hâle getirip bir sonraki nesle aktardığı gibi bilginin paylaşımını da kolaylaştırmaktadır. Medeniyet tarihine bakıldığında da tüm büyük dönüşümlerin yazıyla ilgili olduğu görülmektedir: Bilginin konuşma yoluyla aktarıldığı sözlü kültür; yazının bulunmasıyla başlayan el yazmalı eserlere dayalı kültür; 15. yüzyıl ortalarında matbaanın bulunmasıyla başlayan tipografik (basılı) kültür ve telgrafın bulunması ile başlayan dijital kültür (Donoughue, 2009). Yazma becerisi bireysel gelişim ve akademik başarı için de son derece önemlidir. Bu beceriye sahip olmayan öğrenciler, öğrenme sürecinde yazmaya dayalı etkinliklerde yetersiz kaldıkları veya yazılı sınavlarda bilgilerini tam olarak aktaramadıkları için başarısız olabilmektedirler (Amudson, 2001; Baldini, 2000, Phelps, Stempel ve Speck, 1985).

Yazmayı bireyin izlediklerini, dinlediklerini ve okuduklarını doğru anlamlandırıp zihinde yapılandırdıktan sonra kompozisyon, dil ve abecenin kurallarına uygun olarak, gerekli sembol ve işaretleri kurallarına uygun ve okunaklı olarak üretip yazıya dökme şeklinde tanımlamak mümkündür (Akyol, 2012; Başaran ve Akyol, 2019). Yazı ise seslerle ifade edilen sözcüklerin, gözle görülebilen, işaretler hâlinde kaydedilmesini sağlayan araç (Arseven, 1992) olarak tanımlanabilir.

Yazma, dil becerileri arasında en zor kazanılan beceridir. Bunun sebebi yazmanın, yazarken aynı anda kullanılan, tamamı uygulama ile kazanılan, birbirlerini doğrudan veya dolaylı olarak etkileyen ancak ayrı ayrı düşünülüp geliştirilmesi gereken çok sayıda bilişsel, duyuşsal ve psiko-motor davranışı ustalıkla kullanmayı gerektirmesidir (Baştürk, 2004; Dodd ve Carr, 2003:128; Güneyli, 2006; Power ve Hubbard, 1996: 82).

Yazma her ne kadar bilişsel, duyuşsal ve psiko-motor yönleri olan bir beceri ise de yazma öğretimiyle ilgili literatür (Ak ve Kesik, 2014; Arı, 2010; Ayrancı, 2018; Cömert ve Aktaş, 2011; Çerçi ve Bardakçı, 2016; Erdoğan, 2017; Hamzadayı ve Çetinkaya, 2011; Tok ve Kırbaş ve Orhan, 2011) incelendiğinde, araştırmaların genellikle öğrencilerin yazılı ürünlerinin içeriğine (yazma ile ilgili bilişsel davranışlara) odaklandığı ancak yazmayı etkileyen ergonomik etkenlerin (yazma ile ilgili psiko-motor davranışlar) üzerinde yeterince durulmadığı görülmektedir. Yazma öğretiminde asıl hedef yazının içeriği ve işlevi olsa da 
günlük hayatta yazma becerisinin etkili şekilde kullanılmasında yazının estetik görünmesi de önemlidir.

Her işte olduğu gibi yazmada da ergonomik etkenler öğrencilerin yazılı ürünlerinin niteliği üzerinde etkili olmaktadır. Ergonomi bir iş esnasında araç, gereç veya makinelerin konforlu ve emniyetli bir şekilde kullanılabilmesi için gerekli şartları araştıran bir mühendislik alanıdır (Güler, 2003; Iş11, 1991). Bu tanımdan hareketle yazma ergonomisini de yazma etkinliklerinde gözlenebilen acı duyma, bıkkınlık, sinirlilik, dikkatsizlik, harf çizgilerini doğru şekilde çizememe, kan dolaşımının yavaşlaması, yorgunluk, yavaş ve okunaksız yazma gibi olumsuz durumları önlemek için, öğrencilerin harf çizgilerini çekme yönü, kalem tutma, yazan kolu konumlandırma, boştaki eli konumlandırma ve yazarken doğru şekilde oturma ile ilgili doğru davranışlar olarak tanımlamak mümkündür (Amundson ve Weil, 1996; Beaty ve Bratt, 2007; Havens, 2002; Taylor, 2006). Bu sebepten öğrencilerin yazarken daha az yorulması; daha az hata yapması, daha hızlı ve daha okunaklı yazması için öğretmenlerin, öğrencilerin sadece ne yazdıklarına değil nasıl yazdıklarına da odaklanması gerektiği söylenebilir (Taylor, 2010; Warwick, 2003).

Yazma hızı, yazının niteliği ve yazmaya ilişkin tutumu etkileyen (Akyol, 2005; Amundson, 1995; Beaty ve Bratt, 2007; Havens, 2002; Y1ldız vd. 2015; Taylor, 2006) yazma ergonomisi, temelde kasların ve eklemlerin yapısı, sınırlılıkları ve fonksiyonlarıyla ilgilidir. Harfleri oluştururken tek bir çizgiyi çizmek için bile çok sayıda kas, eklem ve bu kasları çalıştıran/kontrol eden sinir sistemi senkronize şekilde çalışmaktadır. Bu kaslar kısaca şu şekilde açıklanabilir (Barry ve Caffinere, 1981; Biant, 2016; Ellis, 1992; Gürcan ve Adiyaman, 2008; Kahraman, 2001; Lambert, 2016; Lubahn, 1996; Ross, 2016; Uysal, 2003; Valantin, 1981;):

Omuz kasları (deltoideus, subscapularis, supraspinatus, infraspinatus, teres majör ve teres minor) büyük motor hareketleri yapmak için uygun olduklarından yazma esnasında kolun ve elin uygun pozisyonda sabit kalması amaciyla kullanılır. Omuz kasları tarafından yapılan hareketler Şekil 1'de gösterilmektedir. Yazma esnasında omuz kaslarının kola yaptırdığı hareketler kolu vücuttan hafifçe ayırmak ve ileri-aşağı doğru uygun bir açıyla masaya yaklaştırmaktır. 


\begin{tabular}{|l|l|l|l|l|}
\hline Flexion & Extension & Abduction & Adduction & İç ve diş rotasyon \\
\hline
\end{tabular}

Şekil 1. Omuz kasları tarafindan kola yaptırllan hareketler.

(www.researchgate.net/figure/Movement-description-a-Shoulder-flexion-bElevation-inscapula-plane_fig3_318640138)

Önkol kasları (m. palmaris longus, m. pronotor teres, m. flexor carpi radialis, m. flexor carpi ulnaris, m. flexor digitorum, m. flexor digitorum, profundus, m. flexor pollicis longus, superficialis, $\mathrm{m}$. pronotor quadratus, $\mathrm{m}$. brachioradialis, $\mathrm{m}$. extensor carpi radialis longus, $\mathrm{m}$. extensor carpi radialis brevis, m. extensor digitorum, m. extensor digiti minimi, m. extensor carpi ulnaris, m. anconeus, m. supinator, m. abductor pollicis longus, m. extensor pollicis longus, $\mathrm{m}$. extensor pollicis brevis, ve m. extensor indicis) ise yazmada bileği doğru şekilde tutmak ve kelime yazımında kalemi soldan sağa doğru hareket ettirmek için kullanılır. Bu kaslar ön kolun iç ve dış tarafinda bulurlar. Bu kaslar yazma esnasında ince motor hareketlerden ziyade eli yazmak için uygun açıda tutmak ve el ayasının kâğıda sürtmesini engellemek için kullanılmalıdır. Önkolda bulunan kasların ele yaptırdıkları hareketler Şekil. 2'de ve yazma sırasında aktif olarak kullanılan kaslar Şekil 3. ve Şekil 4'te gösterilmiştir.

\begin{tabular}{|c|c|c|c|}
\hline & \\
\hline Flexsion & Extension & Radial ve ulnar deviation & Pronation ve spunation \\
\hline
\end{tabular}

Şekil 2. Önkolda bulunan kasları ele yaptırdıkları hareketler. (www.wfnk.com/2014/09/wrist-input-is-just-starting.) 


\begin{tabular}{|l|l|l|}
\hline & & \\
\hline Flexor ditorum superficialis & Flexor digitorum profunds & Flexor pollicis longus \\
\hline
\end{tabular}

Şekil 3. Önkol önyüzeyinde bulunan ve yazmada aktif görev alan kaslar(www.kenhub.com/en/library/anatomy/the-superficial-flexors-of-the-forearm.)

\begin{tabular}{|c|c|c|c|}
\hline & & & \\
\hline M. brachioradialis & M. extensor digitorum & M. abductor pollicis longus & M. ext. pollicis brevis \\
\hline
\end{tabular}

Şekil 4. Önkol arka yüzeyinde bulunan ve yazmada aktif görev alan kaslar (www.kenhub.com/en/library/anatomy/radial-muscles-of-the-forearm.)

Buraya kadar incelenen kasların görevi kaba motor hareketleri yapmak ve yazarken eli uygun pozisyona getirmektir. Yazma esnasında vücudu uygun pozisyona getirip sabitleyen bel ve sırt kasları da dahil olmak üzere omuz, kol (biceps, triceps) ve önkol kasları yazının okunaklılığı ve hızı üzerinde dolaylı etkiye sahiptir. Oysa yazma işi son derecece küçük ve kontrollü (ince motor) hareketleri yapmayı gerektirmektedir. Yazmada daha çok parmakları hareket ettiren el kasları kullanılmaktadır.

Elin dış tarafında kas bulunmamaktadır. Elin iç tarafında ise çok hassas hareketleri yapmak için özelleşmiş kaslar bulunmaktadır. Elin iç tarafında bulunan tenar bölgede dört, (m. abductor pollicis brevis, m. opponens pollicis, m. flexor pollicis brevis ve adductor pollicis) hipothenar'da dört (m. palmaris brevis, m. abductor digiti minimi, m. flexor digiti minimi brevis ve m. opponens digiti minimi) ve orta bölgede de dört kas (mm. lumbricales, mm. interossei, $\mathrm{mm}$. interossei dorsales ve $\mathrm{mm}$. interossei palmares) olmak üzere toplamda 12 kas bulunmaktadır. Tenar bölgede bulunan kaslar başparmağa abduksion, flexion, oposizyon ve adduction (bkz. Şekil 5.) yaptırdığı için yazma açısından son derce önemli kaslardır. Elin ortasında bulunan kaslar ise özellikle işaret ve orta parmağa flexion, 
extension ve abduksion yaptırdıkları için yazma açısından önemlidir (bkz. Şekil 6. ve 7.). Hypothenar bölgedeki kaslar ise daha çok serçe parmak ve avucun şekillendirilmesi üzerinde etkili oldukları için yazma açısından önemli sayılmamalıdır.

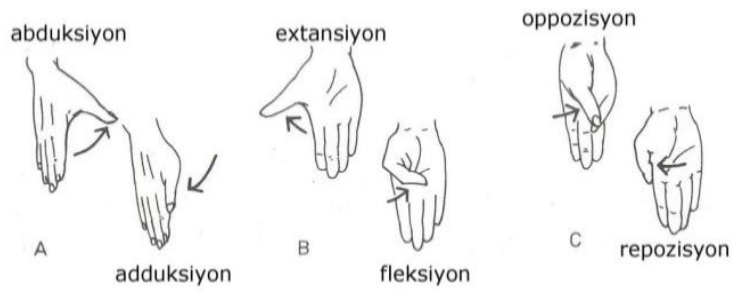

Şekil 5. Başparmak tarafindan yapılan ve yazmada kullanılan

kaslar(www.anatomyinfo.com/hand-muscles.)

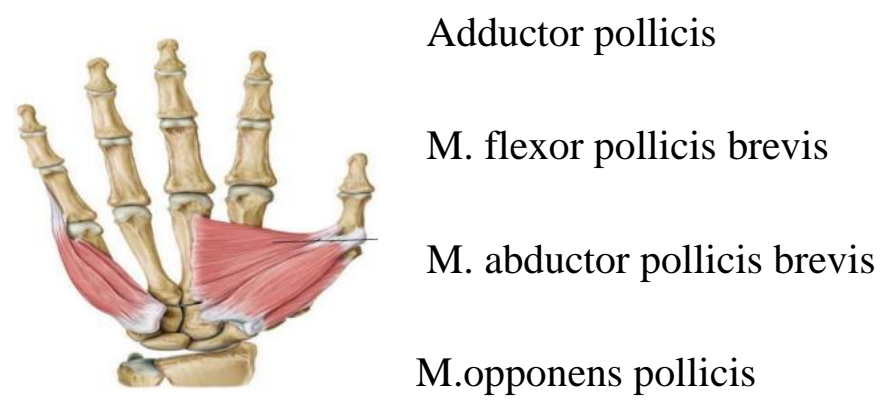

Şekil 6. Tenar bölge kasları (www.anatomyinfo.com/hand-muscles.)

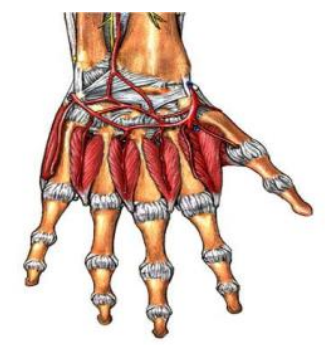

Şekil 7. Elin orta bölgesinde bulunan kaslar (www.anatomyinfo.com/hand-muscles.)

Beynin korteks (dış, nöronların çokça yer aldığı, en gelişmiş) tabakasında belli iş ve işlemler için belli bölgelerin uzmanlaştığı ve bu bölgelerin alanı ne kadar genişse o iş ve işlemlerin o kadar zor, hassas veya karmaşık olduğu bilinmektedir. Vücudun yaptığı bütün hareketlerden yine beynin korteks tabakasinda bulunan "motor korteks" sorumludur (bkz. Şekil 8.). Bu bölge kaslara gönderilen sinirsel uyarıcının başladığı ve kontrol edildiği yerdir. Motor kortekste hangi organların hareketi için ne kadar alanın sorumlu olduğuna bakıldığında en çok alanın el, özellikle başparmak ve yüz kasları için uzmanlaştığı 
görülecektir (bkz. Şekil 9.). Bu sebepten yazma gibi son derece küçük ve kontrollü hareketler gerektiren bir davranış için başparmağın baskın şekilde kullanılması gerektiği söylenebilir.

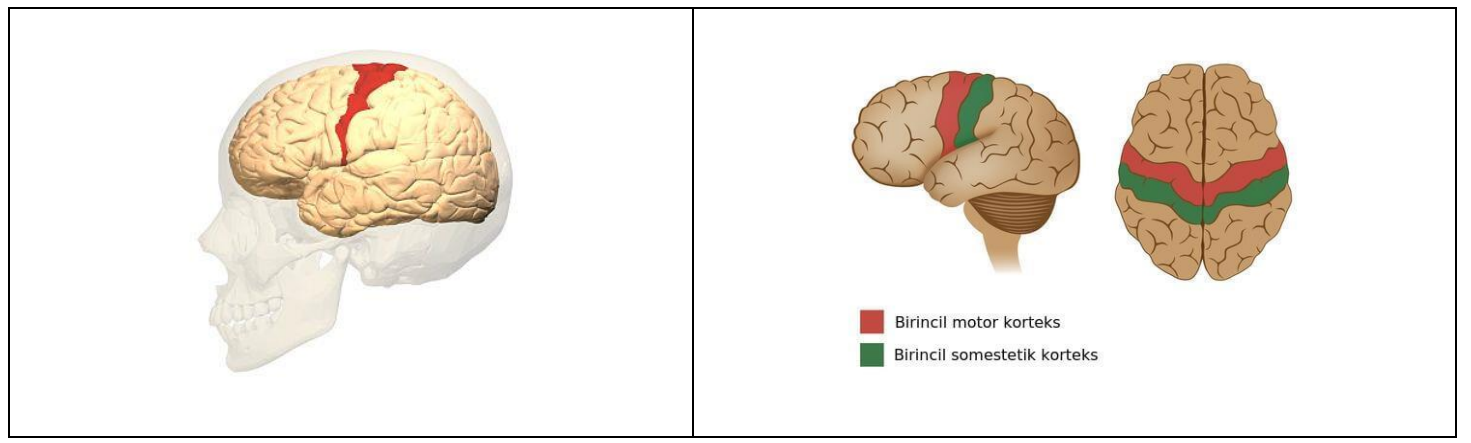

Şekil 8. Motor korteks(www.musicalbrainwaves.weebly.com/motor-cortex.html.)

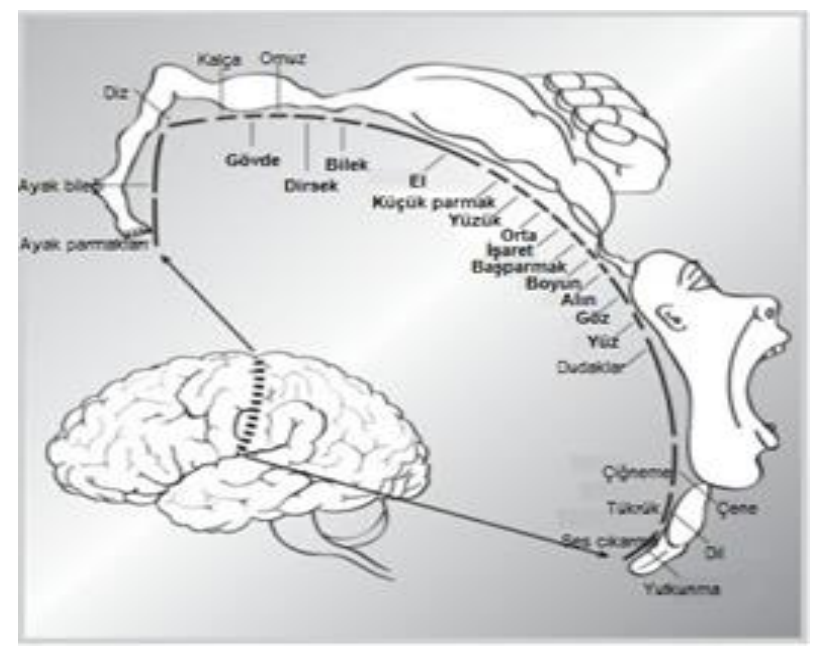

Şekil 9. Motor kortekste kasların hareketlerinden sorumlu alanların büyüklüğ̈̈ (www.zipfslaw.org/2018/08/12/motor-homunculus.)

Görüleceği üzere tek bir harf çizgisini oluşturmak bile son derece karmaşık, eşgüdümlü ve ardışık; ince ve kaba motor hareketler gerektiren zor bir psiko-motor davranıştır. Yazma hızı ve yazının okunaklılığı üzerinde nörolojik ve oturuş şekli, kalemin şekli vb. fiziksel etkenlerin yanında harflerin şekilleri de oldukça etkilidir. Harfler, kullanılan abeceye ve harf tipografisine bağlı olarak muhtelif çizgilerin bir araya getirilmesi sonucu oluşmaktadır. Harflerin hangi kurallar çerçevesinde oluşturulacağı, iki boyutlu yüzeyler üzerinde, tek başlarına veya kelime içinde hangi büyüklük ya da şekilde kullanılacağı ve bir araya geleceği, harf tipografisine bağlıdır (Yücebaş, 2006). Diğer bir deyişle kullanılan yazı karakteri -tipografi- değiştiğinde harfleri oluşturan çizgiler de yapısal olarak değişecektir. Örneğin Latin abecesindeki bitişik eğik yazı tipografisi kullanıldığında 
dik çizgi hiç kullanılmamakta; yatay çizgilerin kullanıldığı yerler azalmakta; sağa veya sola eğik çizgiler ise doğrular şeklinde değil eğriler şeklinde çizilmektedir.

Türkiye'de ilkokuma yazma eğitiminde sınıf öğretmeninin seçimine bağlı olarak dik temel veya bitişik eğik harfler kullanılmaktadır (MEB, 2019: 10). Bu harfler; nokta, dik, eğik, yatay çizgiler, yarım ve tam dairelerin bir araya getirilmesiyle oluşur. Latin abecesinin kökeni bilinen ilk abece olan Fenike abecesine (Bknz. Şekil 1.) dayanmaktadır. Bu abecenin temel özelliği konuşma dilini bir dizi sese ayırıp bu sesler için son derece yalın ve az sayıda semboller atamış olmasıdır (Clair, 1999: 14). Bu abece, Fenikelilerden sonra Romalılar tarafından kullanılmış ve zamanla gelişerek tüm Avrupa'da ve nihayet Güney ve Kuzey Amerika'da da kullanılır hale gelmiştir. Matbaanın icadıyla birlikte bu abecede çok sayıda yazı tipleri/stilleri (tipografi) kullanılmış ancak harflerin karakteristik özellikleri tüm bu stillerde aynı kalmıştır.

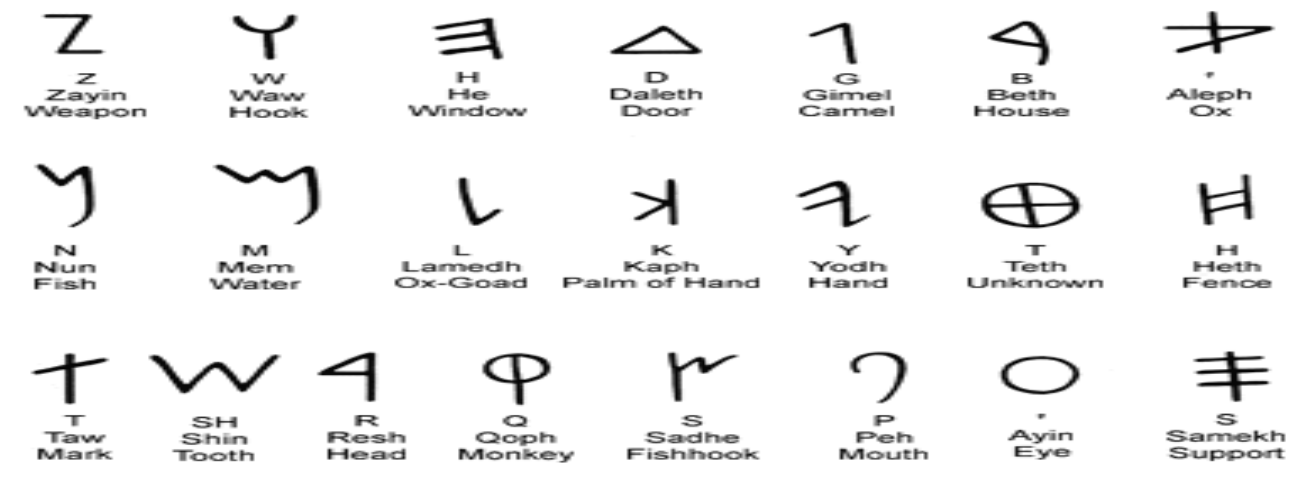

Şekil 10. Fenike Abecesi Figure 10. Phoenician Alphabet (www.alfabesi.com/fenike-alfabesi)

Türkiye'de 1928'den bu yana Latin abecesi kullanılmaktadır. Ancak Türkiye'de kullanılan abece, Latin abecesi kullanan diğer ülkelerdeki abecelerin işleyişinden daha farklıdır. Bu abecede standart Türkçede en çok kullanılan 29 sesi sembolize eden 29 harf bulunmakta; her harf kelime içerisinde başta-ortada-sonda olmasına bakılmaksızın aynı şekilde yazılmakta ve sembolize ettiği ses yanındaki harfle bağlı olmaksızın hiç değişmemektedir. Bu özellikleri dikkate alındığında Türkiye'de kullanılan abecenin Latin abecesini kullanan diğer ülkelerdeki abecelerin hiçbirine benzemediği; oldukça basit ve istisnasız kurallara göre işlediği görülmektedir. Ancak Türkiye'de kullanılan abece oldukça basit olmasına rağmen, özellikle son 20 yıldır, ilk okuma yazmanın öğretiminde hangi yöntemin ve bu yönteme uygun hangi yazı tipografisininin kullanılacağına ilişkin tartışmalar devam etmektedir (Akyol 2012, Baştuğ ve Demirtaş, 2016; Güneş, 2017; Kırmızı ve Ünal, 2016; Öz ve Çelik, 2015). 
MEB Türkçe dersi öğretim programları incelendiğinde de ilkokuma yazmada kullanılacak yöntem ve harf tipografisi üzerinde bilgiler verildiği; yazma eğitiminde yazma ergonomisine dikkat çekildiği (MEB, 2019: 10) ancak harf çizgilerinin çizim yönlerinin üzerinde durulmadığı görülmektedir (MEB, 2006; MEB, 2010; MEB, 2015; MEB, 2018; MEB, 2019). Yazma hızı, yazının okunaklılı̆̆ı ve yazma ergonomisiyle ile ilgili çalışmalara bakıldığında da harf çizgilerini çizme yönü, çizme hızı ve çizgi niteliği üzerinde yeterince durulmadığı görülmektedir. $\mathrm{Bu}$ araştırmalarda genellikle yazma hızı ve yazı niteliği ile kalemin şekli (Alston, 1986; Halıcı, 2019), yazı biçemi (Bara, 2013), yaş, okul, sınıf, cinsiyet, kullanılan el, kağıdın duruşu, kalem tutuş, vücudun duruşu, yazılan metnin türü, yerleşim yeri, okul öncesi eğitim alma (Arslan ve Bağc1, 2017; Arslan ve Ilgın, 2010; Çevik, 2006; Doğan, 2007; Duran, 2011; Erdoğan, 2012; Höbek ve Taşkaya, 2018; Vlachos ve Bonoti, 2006; Yıldız vd. 2015), sınıf öğretmeni (Başaran, 2006; Bayraktar, 2006) sıra tasarımı (Kavak ve Bumin, 2009; Medwell ve Wray, 2007) görsel alg1 (Memiş ve Harmankaya, 2012) kalemi s1kma gücü (Schneck, 1991; Schneck ve Henderson, 1990; Summers ve Catarro, 2003) ve öğrenme güçlüğü (Blöte ve Hamstra, 1991; Fatemeh vd., 2008; Hamstra ve Blöte, 1993; Overlede vd. 2011) arasındaki ilişki üzerinde durulmuştur. Oysa çizgileri çizme yönü de harflerin tipografisi ve yazmanın ergonomisiyle ilgili olup çizgi çizme hızı ve çizgi niteliğini dolayısıyla yazma hızı ve yazının okunaklılığını etkileme potansiyeline sahiptir (Dennis ve Swinth, 2001; Koziatek ve Powell, 2003; Tseng, 1998; Brink ve Jacobs, 2011; Graham vd., 2006; Graham vd., 1998; Palmis vd., 2017; Tseng ve Cermak, 1993).

\section{Araştırmanın Amacı}

$\mathrm{Bu}$ araştırmada harf çizgilerini çizme yönünün yazma hızı ve çizgilerin niteliği üzerindeki etkisinin tespiti amaçlanmıştır. Bu amaç doğrultusunda araştırmada şu alt problemlere cevap aranmıştır: 
1- Çizgi çizme yönü ile çizme hızı ve çizgi niteliği arasında bir ilişki var mıdır?

2- Kılavuz çizgiler yardımıyla harf çizgilerini çizme ile çizme hızı ve çizgi niteliği arasında bir ilişki var mıdır?

3- Cinsiyet ile çizme hızı ve çizgi niteliği arasında bir ilişki var mıdır?

4- Sınıf düzeyi ile çizme hızı ve çizgi niteliği arasında bir ilişki var mıdır?

\section{Yöntem}

$\mathrm{Bu}$ araştırmada karma yöntem kullanılmıştır. Karma yöntem, bir çalı̧̧ma veya birbirini izleyen çalışmalar içerisinde nitel ve nicel paradigma, yöntem veya tekniklerin beraberce kullanılması olarak tanımlanabilir. Araştırmada karma yöntemin kullanılmasının temel nedeni, bu yöntemin yapısı gereği "tamamlayıc1lk" (complementarity) işlevini taşıyor olmasıdır. Buna göre karma yöntemle nitel ve nicel veriler birlikte kullanılarak birbirini destekleyip desteklemediği ortaya çıkmakta veya bu veriler beraberce yorumlanarak anlamlandırılmaktadır. Bu sayede araştırma sonuçları daha da zenginleştirilebilmektedir (Butgel vd., 2016; Tashakkori ve Teddlie, 2003). Araştırmada harf çizgilerini çizme yönü ile çizme hızı arasındaki ilişkiyi tespit etmek amacıyla nicel araştırma yöntemlerinden ilişkisel tarama; çizgilerin niteliği arasındaki ilişkiyi tespit etmek için nitel araştırma yöntemlerinden doküman analizi kullanılmıştır.

İlişkisel tarama yöntemi, nicel araştırma yöntemlerinden tarama desenleri arasında yer almaktadır. $\mathrm{Bu}$ desende birden çok durum arasındaki ilişkinin varlığı, ilişki varsa derecesi araştırmacının müdahalesi olmadan incelenmektedir (Creswell, 2011; Karasar, 2013). Doküman analizinde ise araştııılması hedeflenen olgu veya olaylar hakkında bilgi içeren yazılı, sözlü veya görsel materyallerin analizi yapılmaktadır. Doküman analizi ile elde edilen verileri derinlemesine incelemek, bu sayede elde edilen veriler arasındaki ilişkileri de ortaya çıkarmak mümkün olmaktadır (Fitzgerald, 2012; Yıldırım ve Şimşek, 2013).

\section{Çalışma Grubu}

Çalışma grubu belirlenirken araştırmanın deseni gereği amaçlı örnekleme tekniklerinden ölçüt örnekleme kullanılmıştır. Amaçlı örnekleme teknikleri, araştırmanın yöntemi ve amacı açısından uygun ve zengin bilgiye sahip olduğu düşünülen durumların derinlemesine incelenmesine imkân sağlamaktadır. Ölçüt örnekleme ise çalışma grubunun belli niteliklere sahip kişiler, olaylar, nesneler veya durumlardan seçilip oluşturulmasıdır. Diğger bir deyişle örneklem için belirlenen ölçütü karşılayan birimlerin örnekleme alınmasıdır (Büyüköztürk, 
2010; Patton, 2002; Yıldırım ve Şimşek, 2013). Bu çalışmada İstanbul ili Esenler ve Zeytinburnu ilçelerinde bulunan devlet ilkokullarında öğrenimlerine devam eden 1, 2, 3 ve 4. sınıf öğrencileri çalışma evrenini oluşturmaktadır. Bu evrenden 41'i 1, 39'u 2, 40'1 3 ve 44'ü 4. sınıf olmak üzere toplam 164 öğrenciye ulaşılmıştır. Bu öğrenciler örnekleme dâhil edilirken öğrencilerin,

1. Disleksi ve disgrafya gibi okuma-yazma ile ilgili özel öğrenme güçlüğünün bulunmamasina

2. Yazma ile ilgili fizyolojik bir engelinin olmamasına

3. Göçmen statüsündeki ailelerin çocuğu olmamasına

4. Yazarken dik temel harfleri kullanmasına

5. Kalem tutma, kâğıdı konumlandırma ve sıraya oturmayla ilgili doğru davranışlara sahip olmasına bakılmıştır.

Bu sayede araştırmada elde edilen sonuçların sadece çizgileri çizme yönünden etkilenmesi; yazma hızı ve çizgi kalitesini etkileyebilecek diğer değişkenlerin kontrol altına alınması amaçlanmıştır.

\section{Veri Toplama Araçları}

Araştırmada araştırmacı tarafından geliştirilen ölçme araçları kullanılmıştır. Çalışmada önce öğrencilerin dik temel harflerin yazımında en çok kullanılan daire, dik, sola eğik, sağa eğik ve yatay çizgileri (Akyol, 2012; Binbaşığlu, 2004) çizme yönünün çizgi çizme süresi üzerindeki etkilerini tespit etmek amacıyla geliştirilen Çizgi Çizme Yönünün Çizgi Çizme Hızını Etkileme Durumunu Belirleme Ölçeği kullanılmıştır (Ek: 1). Yarım daire ise çok az kullanıldığı ve harflerin özelliklerine göre şekli/konumu değiştiği için ölçme aracına dâhil edilmemiş̧tir. Araştırmanın amacı gereği, bu çizgilerin hangi yöne doğru çizileceği de ölçme aracında gösterilmiştir: Öğrencilerden dik çizgiyi yukarıdan aşağıya ve aşağıdan yukarıya; sola eğik ve sağa eğik çizgiyi, sağ üstten sol alta, sol alttan sağ üste; sol üstten sağ alta ve sağ alttan sol üste; yatay çizgiyi, soldan sağa ve sağdan sola; daireyi ise saat yönünde ve saat yönünün tersine çizmeleri istenmiştir. Öğrencilerden -çizdikleri tek bir çizginin çizgi çizme hızı ve çizgilerinin niteliğini gösteremeyeceği göz önüne alınarak- her bir çizgiden 10 adet çizmeleri istenmiş ve veriler 10 çizgi üzerinden elde edilmiştir. Bu ölçekte ayrıca, kılavuz çizgiler yardımıyla ve kılavuz çizgiler olmaksızın çizgi çizmenin, çizgi çizme hızı ve çizgi niteliği üzerindeki etkisini tespit etmek amacıyla da düzenleme yapılmıştır. Ölçeğin 
geçerliliği doktorasını Türkçe öğretimi alanında yapmış beş uzmanın görüşü alınarak sağlanmıştır.

Çizgilerin niteliğini belirlemek için yine araştırmacı tarafından geliştirilen Çizgi Niteliğini Belirleme Formu kullanılmıştır (Ek 2). Bu ölçme aracı, öğrencinin çizdiği çizginin belirlenen özelliklere ne ölçüde sahip olduğunu tespit etmek amacıyla bir gözlem formu şeklinde düzenlenmiştir. Ölçeğin geçerliliği Türkçenin öğretimi alanında doktorasını tamamlamış beş alan uzmanın görüşü alınarak sağlanmıştır. Çizgiler için dokuz ölçüt belirlenmiştir. Öğrencilerin çizdiği 10 çizginin geneli bir ölçütteki durumu yansıtıyorsa öğrenciye ilgili ölçütten " 1 ” değilse " 0 ” puan verilmiştir. Bu ölçekten bir öğrencinin alabileceği en yüksek puan 9 ve en düşük puan 0'dır. Bu sebepten toplam puanı 0-3 arası olan çizgiler grubu düşük; 4-6 puan arası olanlar orta ve 7-9 puan arası olanlar ise iyi nitelikte olarak değerlendirilmesi uygun görülmüştür.

\section{Veri Toplama Süreci}

Araştırmanın bütün aşamaları, araştırmacı tarafından yürütülmüştür. Verilerin toplanma sürecinde tüm uygulamalar sınıf ortamında gerçekleştirilmiştir. İstanbul'un Esenler ve Zeytinburnu ilçesinde birer devlet okulu belirlenmiş, bu okulların 1, 2, 3, ve 4. sınıflarının sınıf öğretmenleri ile görüşülmüş, araştırmaya dâhil edilecek öğrencilerin nitelikleri bu öğretmenlere anlatılmıştır. Gönüllü öğretmenlerin sınıflarında, öğretmenlerin önerdiği öğrenciler yazı yazmayı gerektiren etkinlerde gözlenmiş ve o sınıfta hangi öğrencilerle çalışılacağı tespit edilmiştir. Tespit edilen öğrencilere "Çizgi Çizme Yönünün Çizgi Çizme Hızını Etkileme Durumunu Belirleme Ölçeği” uygulanmıştır. Öğrenciler ölçekte gösterilen şekilde 10 çizgiyi çektikten sonra bu işlemin ne kadar sürdüğü kaydedilmiş ardından öğrenciden sonraki 10 çizgiyi çizmesi istenmiştir. Tüm süreç video ile kayıt altına alınmıştır. Araştırmanın ikinci aşamasında ise çizgilerin niteliğinin tespiti yapılmıştır. Bunun için "Çizgi Niteliğini Belirleme Gözlem Formu” kullanılmıştır. Öğrencilerin çektiği çizgiler, Türkçe öğretimi alanında doktorasını tamamlamış bir alan uzmanı ve yüksek lisansını bu alanda tamamlamış iki alan uzmanı tarafından ayrı ayrı puanlanmıştır. Uzmanların farklı puan verdiği öğrenciler için çizgiler üç uzman tarafından birlikte tekrar incelenmiş ve o öğrencinin çizgilerine uzmanların mutabakat sağladığı puan verilmiştir.

\section{Bulgular}

$\mathrm{Bu}$ bölümde araştırma sonucu ulaşılan bulgular tablolar hâlinde sunulmuş ve yorumlanmıştır. Tablolarda bazı kısaltmalar kullanılmıştır. Bu kısaltmalar şunlardır: 
Tablo 1.'de ilkokul 1, 2, 3, ve 4. sınıfa devam eden öğrencilerin onar adet dik çizgiyi yukarıdan aşağıya ve aşağıdan yukarıya; sağa eğik çizgiyi sağ-üst köşeden sol-alta, sol-alt köşeden sağ-üste; sola eğik çizgiyi sol-üst köşeden sağ alta ve sağ alt köşeden sol-üst köşeye; yatay çizgiyi soldan sağa ve sağdan sola çizmeleri ile daireyi saat yönünde ve saat yönünün tersine çizme sürelerinin anlamlı bir fark yaratıp yaratmadığına bakılmıştır. Tablo 1. incelendiğinde $1,2,3$, ve 4 . sınıf düzeyinde dik, eğik, yatay çizgiler ile daire çizmede çizgi çekim yönünün çizginin çekim süresi üzerinde anlamlı bir etkisinin olmadığ görülmektedir ( $>$ >.05).

Tablo 1. Harf Çizgilerini Çizme Yönünü ile Çizgi Çizme Hızı (sn.) Arasındaki İlişki

\begin{tabular}{|c|c|c|c|c|c|c|}
\hline Sinif & $\begin{array}{l}\text { Çizgi/çizgi } \\
\text { yönü }\end{array}$ & $\mathrm{N}$ & $\mathrm{X}$ & $S$ & $\mathrm{t}$ & $\mathrm{p}$ \\
\hline 1 & YADÇ & 41 & 22,11 & 11,77 &, 511 & 611 \\
\hline \multirow[t]{9}{*}{$\mathrm{Sd}=80$} & AYDÇ & 41 & 23,42 & 11,35 & & \\
\hline & YASEÇ & 41 & 22,45 & 10,53 & ,339 & ,735 \\
\hline & AYSEÇ & 41 & 23,21 & 9,85 & & \\
\hline & YASOEÇ & 41 & 22,52 & 8,83 &, 150 & ,881 \\
\hline & AYSOEÇ & 41 & 22,83 & 9,71 & & \\
\hline & SOSYÇ & 41 & 21,21 & 9,48 & ,337 & ,737 \\
\hline & SASYÇ & 41 & 21,92 & 9,63 & & \\
\hline & SYTD & 41 & 17,40 & 6,13 & ,409 & ,684 \\
\hline & SYD & 41 & 17,97 & 6,49 & & \\
\hline 2 & YADÇ & 39 & 20,87 & 12,82 & 1,277 & ,205 \\
\hline \multirow[t]{9}{*}{$\mathrm{Sd}=76$} & AYDÇ & 39 & 24,56 & 12,71 & & \\
\hline & YASEÇ & 39 & 21,82 & 10,32 & ,808 &, 422 \\
\hline & AYSEÇ & 39 & 23,92 & 12,55 & & \\
\hline & YASOEÇ & 39 & 20,46 & 10,56 & 903 &, 370 \\
\hline & AYSOEÇ & 39 & 22,58 & 10,25 & & \\
\hline & SOSYÇ & 39 & 20,30 & 9,27 & 1,105 &, 273 \\
\hline & SASYÇ & 39 & 22,66 & 9,57 & & \\
\hline & SYTD & 39 & 15,64 & 6,38 & 1,222 & ,225 \\
\hline & SYD & 39 & 17,51 & 7,12 & & \\
\hline 3 & YADÇ & 40 & 18,56 & 6,09 & 1,329 &, 188 \\
\hline $\mathrm{Sd}=79$ & AYDÇ & 40 & 20,54 & 7,23 & & \\
\hline
\end{tabular}




\begin{tabular}{|c|c|c|c|c|c|c|}
\hline & \multicolumn{5}{|c|}{ Başaran, M./ Pamukkale Üniversitesi Ĕ̈itim Fakültesi Dergisi, 52, 86-118, 2021} & \multirow{2}{*}{$\begin{array}{l}99 \\
, 500\end{array}$} \\
\hline & YASEÇ & 40 & 18,51 & 10,86 &, 678 & \\
\hline & AYSEÇ & 40 & 19,80 & 5,76 & & \\
\hline & YASOEÇ & 40 & 16,48 & 5,24 & 2,056 &, 051 \\
\hline & AYSOEÇ & 40 & 18,85 & 5,34 & & \\
\hline & SOSYÇ & 40 & 18,05 & 5,95 &, 857 & ,394 \\
\hline & SASYÇ & 40 & 19,14 & 5,50 & & \\
\hline & SYTD & 40 & 15,05 & 5,35 &, 570 &, 571 \\
\hline & SYD & 40 & 15,66 & 4,35 & & \\
\hline 4 & YADÇ & 44 & 18,46 & 4,81 & 1,468 & , 177 \\
\hline \multirow[t]{9}{*}{$\mathrm{Sd}=76$} & AYDÇ & 44 & 19,18 & 6,36 & & \\
\hline & YASEÇ & 44 & 17,62 & 3,49 & 1,327 &, 188 \\
\hline & AYSEÇ & 44 & 18,81 & 4,90 & & \\
\hline & YASOEÇ & 44 & 17,46 & 4,51 & 1,388 &, 169 \\
\hline & AYSOEÇ & 44 & 18,63 & 5,66 & & \\
\hline & SOSYÇ & 44 & 17,33 & 4,52 & 1,183 &, 240 \\
\hline & SASYÇ & 44 & 18,36 & 3,62 & & \\
\hline & SYTD & 44 & 14,35 & 4,90 &, 448 & ,655 \\
\hline & SYD & 44 & 14,77 & 3,79 & & \\
\hline
\end{tabular}

Not: YADÇ: Yukarıdan aşağıya çizilmiş dik çizgi, AYDÇ: Aşağıdan yukarıya çizilmiş dik çizgi, YASEÇ: Yukarıdan aşağıya çizilmiş sağa eğik çizgi, AYSEÇ: Aşağıdan yukarıdan çizilmiş sağa eğik çizgi, YASOEÇ: Yukarıdan aşağıya çizilmiş sola eğik çizgi, AYSOEÇ: Aşağıdan yukarıdan çizilmiş sola eğik çizgi, SOSYÇ: Soldan sağa çizilmiş yatay çizgi, SASYÇ: Sağdan sola çizilmiş yatay çizgi, SYTD: Saat yönünün tersine çizilmiş daire, SYD: Saat yönünde çizilmiş daire

Ancak tablodaki betimsel veriler incelendiğinde, tüm sınıf seviyelerinde dik, sağa ve sola eğik çizgilerin yukarıdan aşağıya; yatay çizgilerin soldan sağa daha hızlı çekildiği; dairenin diğer çizgilere kıyasla daha hızlı çizildiği ayrıca daire çiziminde çizgi çizme yönünün diğer çizgilere göre hız üzerinde en az etkili olduğu söylenebilir.

Tablo 2. Harf Çizgilerini Çizme Yönünü ile Çizgilerin Niteliği Arasındaki İlişki

\begin{tabular}{lllllll}
\hline Sinıf & $\begin{array}{l}\text { Çizgi/çizgi } \\
\text { yönü }\end{array}$ & N & X & S & t & p \\
& YADÇ & 41 & 2,69 &, 51 & 3,164 &, 002 \\
Sd=80 & AYDÇ & 41 & 2,20 &, 85 & & \\
& YASEÇ & 41 & 2,53 &, 74 & 1,995 &, 049 \\
& AYSEÇ & 41 & 2,15 &, 86 & &
\end{tabular}




\begin{tabular}{|c|c|c|c|c|c|c|}
\hline & YASOEÇ & 41 & 2,52 & ,76 & \multirow[t]{2}{*}{1,955} & \multirow[t]{2}{*}{,058 } \\
\hline & AYSOEÇ & 41 & 2,17 &, 84 & & \\
\hline & SOSYÇ & 41 & 2,38 & ,66 & \multirow[t]{2}{*}{, 385} & \multirow[t]{2}{*}{, 702} \\
\hline & SASYÇ & 41 & 2,32 & ,65 & & \\
\hline & SYTD & 41 & 1,95 & ,66 & \multirow{2}{*}{1,462} & \multirow[t]{2}{*}{,148 } \\
\hline & SYD & 41 & 1,75 &, 58 & & \\
\hline 2 & YADÇ & 39 & 2,46 & ,71 & 3,541 & ,001 \\
\hline \multirow[t]{9}{*}{$\mathrm{Sd}=76$} & AYDÇ & 39 & 1,84 &, 81 & & \\
\hline & YASEÇ & 39 & 2,25 &, 81 & \multirow[t]{2}{*}{2,222} & \multirow[t]{2}{*}{,029 } \\
\hline & AYSEÇ & 39 & 1,84 &, 81 & & \\
\hline & YASOEÇ & 39 & 2,17 &, 72 & \multirow[t]{2}{*}{,620 } & \multirow[t]{2}{*}{, 537} \\
\hline & AYSOEÇ & 39 & 2,07 &, 73 & & \\
\hline & SOSYÇ & 39 & 2,30 & ,65 & \multirow[t]{2}{*}{1,318} & \multirow[t]{2}{*}{,191 } \\
\hline & SASYÇ & 39 & 2,10 &, 71 & & \\
\hline & SYTD & 39 & 1,89 &, 75 & \multirow[t]{2}{*}{2,061} & \multirow[t]{2}{*}{, 043} \\
\hline & SYD & 39 & 1,58 &, 54 & & \\
\hline 3 & YADÇ & 40 & 2,38 & ,74 & 1,538 &, 128 \\
\hline \multirow[t]{9}{*}{$\mathrm{Sd}=78$} & AYDÇ & 40 & 2,11 &, 80 & & \\
\hline & YASEÇ & 40 & 2,46 &, 75 & \multirow{2}{*}{1,109} & \multirow[t]{2}{*}{, 271} \\
\hline & AYSEÇ & 40 & 2,26 &, 85 & & \\
\hline & YASOEÇ & 40 & 2,41 &, 71 & \multirow[t]{2}{*}{,482 } & \multirow[t]{2}{*}{,631 } \\
\hline & AYSOEÇ & 40 & 2,33 &, 72 & & \\
\hline & SOSYÇ & 40 & 2,41 & ,63 & \multirow[t]{2}{*}{, 037} & \multirow[t]{2}{*}{,971 } \\
\hline & SASYÇ & 40 & 2,40 &, 70 & & \\
\hline & SYTD & 40 & 1,98 &, 82 & \multirow[t]{2}{*}{2,596} & \multirow[t]{2}{*}{,011 } \\
\hline & SYD & 40 & 1,83 &, 72 & & \\
\hline 4 & YADÇ & 44 & 1,95 & ,90 &, 363 &, 718 \\
\hline \multirow[t]{9}{*}{$\mathrm{Sd}=86$} & AYDÇ & 44 & 1,88 & ,89 & & \\
\hline & YASEÇ & 44 & 2,17 &, 86 & \multirow[t]{2}{*}{,959 } & \multirow[t]{2}{*}{, 340} \\
\hline & AYSEÇ & 44 & 2,00 &, 88 & & \\
\hline & YASOEÇ & 44 & 2,22 &, 76 & ,776 & ,440 \\
\hline & AYSOEÇ & 44 & 2,09 &, 83 & & \\
\hline & SOSYÇ & 44 & 2,22 &, 80 & , 159 &, 874 \\
\hline & SASYÇ & 44 & 2,20 &, 81 & & \\
\hline & SYTD & 44 & 2,00 & ,90 & 2,391 & ,019 \\
\hline & SYD & 44 & 1,89 &, 69 & & \\
\hline
\end{tabular}

Not: YADÇ: Yukarıdan aşağıya çizilmiş dik çizgi, AYDÇ: Aşağıdan yukarıya çizilmiş dik çizgi, YASEÇ: Yukarıdan aşağıya çizilmiş sağa eğik çizgi, AYSEÇ: Aşağıdan yukarıdan çizilmiş sağa eğik çizgi, YASOEÇ: Yukarıdan aşağıya çizilmiş sola eğik çizgi, AYSOEÇ: Aşağıdan yukarıdan çizilmiş sola eğik çizgi, SOSYÇ: Soldan sağa çizilmiş yatay çizgi, SASYÇ: Sağdan sola çizilmiş̧ yatay çizgi, SYTD: Saat yönünün tersine çizilmiş daire, SYD: Saat yönünde çizilmiş daire

Tablo 2. incelendiğinde harf çizgilerini çizme yönünün 1. ve 2. sınıfta dik çizgi, sağa eğik çizgi ve daire; 3. ve 4. sınıfta ise dairenin niteliği üzerinde anlamlı bir fark yarattığı 
diğer harf çizgileri üzerinde ise anlamlı bir farka neden olmadığ 1 görülmektedir (p<.05). Bu sonuçlar ilgili betimsel verilerle birlikte incelendiğinde dik ve sağa eğik çizgiyi yukarıdan aşağıya doğru çizmenin, çizginin niteliğini artırdığı söylenebilir. Ayrıca 1-4. sınıf seviyesinde dairenin saat yönünün tersine doğru çizilmesi daire çizgisinin niteliğini artırmaktadır. Ancak tablodaki betimsel veriler incelendiğinde, tüm sınıf seviyelerinde dik, sağa ve sola eğik çizgilerin yukarıdan aşağıya; yatay çizgilerin soldan sağa; dairenin ise saat yönünün tersine çizildiği durumda çizgilerin daha nitelikli olduğu söylenebilir. Ayrıca tabloya göre her sınıf düzeyinde daire için çizilen çizgilerin en az nitelikli çizgiler olduğu görülmektedir.

Tablo 3. Cinsiyet Değişkeni ile Çizgi Çizme Hızı Arasındaki İlişki

\begin{tabular}{|c|c|c|c|c|c|c|c|c|}
\hline \multirow{2}{*}{$\begin{array}{c}\text { Değişken } \\
\mathrm{Sd}=162\end{array}$} & \multicolumn{3}{|c|}{$\mathrm{K} 1 \mathrm{Z}$} & \multicolumn{3}{|c|}{ Erkek } & \multirow[t]{2}{*}{$\mathrm{t}$} & \multirow[t]{2}{*}{$\mathrm{p}$} \\
\hline & $\mathrm{N}$ & $X$ & $S$ & $\mathrm{~N}$ & $X$ & $S$ & & \\
\hline YADÇ & 88 & 15,94 & 8,04 & 76 & 21,88 & 12,08 & 3,379 & ,000 \\
\hline AYDÇ & 88 & 18,71 & 5,28 & 76 & 19,53 & 6,16 & ,921 &, 358 \\
\hline YASEÇ & 88 & 19,43 & 7,42 & 76 & 21,25 & 8,89 & 1,427 &, 156 \\
\hline AYSEÇ & 88 & 18,80 & 5,26 & 76 & 19,57 & 5,94 & ,882 & ,379 \\
\hline YASOEÇ & 88 & 17,86 & 7,52 & 76 & 20,39 & 9,01 & 1,960 &, 052 \\
\hline AYSOEÇ & 88 & 17,93 & 4,56 & 76 & 19,13 & 6,00 & 1,451 &, 149 \\
\hline SOSYÇ & 88 & 18,02 & 6,01 & 76 & 20,56 & 9,10 & 2,135 & ,034 \\
\hline SASYÇ & 88 & 18,44 & 3,82 & 76 & 18,46 & 4,62 & ,026 & ,979 \\
\hline SYTD & 88 & 15,70 & 6,29 & 76 & 15,92 & 5,27 & ,237 & ,813 \\
\hline SYD & 88 & 14,69 & 4,15 & 76 & 16,14 & 4,65 & 2,111 & ,036 \\
\hline
\end{tabular}

Not: YADÇ: Yukarıdan aşağıya çizilmiş dik çizgi, AYDÇ: Aşağıdan yukarıya çizilmiş dik çizgi, YASEÇ: Yukarıdan aşağıya çizilmiş sağa eğik çizgi, AYSEÇ: Aşağıdan yukarıdan çizilmiş sağa eğik çizgi, YASOEÇ: Yukarıdan aşağıya çizilmiş sola eğik çizgi, AYSOEÇ: Aşağıdan yukarıdan çizilmiş sola eğik çizgi, SOSYÇ: Soldan sağa çizilmiş yatay çizgi, SASYÇ: Sağdan sola çizilmiş yatay çizgi, SYTD: Saat yönünün tersine çizilmiş daire, SYD: Saat yönünde çizilmiş daire

Tablo 3'te cinsiyet değişkeninin çizgileri çizme hızı üzerindeki etkisine yönelik veriler yer almaktadır. Cinsiyet değişkeninin yukarıdan aşağıya dik, soldan sağa yatay çizgi ile saat yönünde çizilen dairenin çizilme hızı üzerinde anlamlı bir etkisi vardır $(\mathrm{p}<.05)$. Bu sonuç, ilgili betimsel verilerle beraber incelendiğinde kız öğrencilerin dik çizgiyi yukarıdan aşağıya, yatay çizgiyi soldan sağa ve daireyi saat yönünde daha hızlı çizdiği şeklinde yorumlanabilir. Ayrıca tablodaki tüm betimsel veriler bir bütün olarak incelendiğinde kız öğrencilerin tüm harf çizgilerini daha hızlı çektiği söylenebilir. 
Tablo 4. Cinsiyet Değişkeni ile Çizgilerin Niteliği Arasındaki İlişki

\begin{tabular}{lcccccccc}
\hline Değişken & \multicolumn{9}{c}{ Kız } & \multicolumn{7}{c}{ Erkek } & $\mathrm{t}$ & $\mathrm{p}$ \\
\cline { 2 - 6 } Sd=162 & $\mathrm{N}$ & $\mathrm{X}$ & $\mathrm{S}$ & $\mathrm{N}$ & $\mathrm{X}$ & $\mathrm{S}$ & & \\
\hline YADÇ & 88 & 2,51 &, 66 & 76 & 2,40 &, 73 &, 944 &, 346 \\
AYDÇ & 88 & 2,26 &, 80 & 76 & 2,02 &, 81 & 1,847 &, 067 \\
YASEÇ & 88 & 2,44 &, 80 & 76 & 2,38 &, 73 &, 507 &, 613 \\
AYSEÇ & 88 & 2,13 &, 92 & 76 & 2,27 &, 77 & 1,040 &, 300 \\
YASOEÇ & 88 & 2,30 &, 71 & 76 & 2,42 &, 67 & 1,043 &, 298 \\
AYSOEÇ & 88 & 2,28 &, 74 & 76 & 2,31 &, 69 &, 281 &, 779 \\
SOSYÇ & 88 & 2,25 &, 69 & 76 & 2,50 &, 56 & 2,535 &, 012 \\
SASYÇ & 88 & 2,20 &, 77 & 76 & 2,34 &, 74 & 1,157 &, 249 \\
SYTD & 88 & 1,96 &, 77 & 76 & 2,22 &, 74 & 2,264 &, 025 \\
SYD & 88 & 1,75 &, 63 & 76 & 1,77 &, 81 &, 197 &, 844 \\
\hline
\end{tabular}

Not: YADÇ: Yukarıdan aşağıya çizilmiş dik çizgi, AYDÇ: Aşağıdan yukarıya çizilmiş dik çizgi, YASEÇ: Yukarıdan aşağıya çizilmiş sağa eğik çizgi, AYSEÇ: Aşağıdan yukarıdan çizilmiş sağa eğik çizgi, YASOEÇ: Yukarıdan aşağıya çizilmiş sola eğik çizgi, AYSOEÇ: Aşağıdan yukarıdan çizilmiş sola eğik çizgi, SOSYÇ: Soldan sağa çizilmiş yatay çizgi, SASYÇ: Sağdan sola çizilmiş yatay çizgi, SYTD: Saat yönünün tersine çizilmiş daire, SYD: Saat yönünde çizilmiş daire

Tablo 4'te cinsiyet değişkeninin çizgilerin niteliği üzerindeki etkisine yönelik veriler yer almaktadır. Cinsiyet değişkeninin soldan sağa yatay çizgi ile saat yönünde çizilen dairenin niteliği üzerinde anlamlı bir etkisi vardır $(\mathrm{p}<.05)$. Bu sonuç ilgili betimsel verilerle beraber incelendiğinde kız öğrencilerin çizdiği soldan sağa yatay çizgi ve saat yönünde çizdiği dairenin daha nitelikli olduğu, diğer harf çizgilerinin üzerinde ise anlamlı bir etkisinin olmadığ 1 görülmüştür.

Tablo 5. Kılavuz Çizgileri ile Çizgi Çizme Hızı Arasındaki İlişki

\begin{tabular}{lcccccccc}
\hline \multirow{2}{*}{ Değişken } & \multicolumn{7}{c}{ Kilavuz çizgisi var } & \multicolumn{7}{c}{ Kilavuz çizgisi yok } & \multirow{2}{*}{$\mathrm{t}$} & $\mathrm{p}$ \\
\cline { 2 - 7 } & $\mathrm{N}$ & $\mathrm{X}$ & $\mathrm{S}$ & $\mathrm{N}$ & $\mathrm{X}$ & $\mathrm{S}$ & & \\
\hline YADÇ & 164 & 19,15 & 9,66 & 164 & 16,18 & 6,55 & 3,038 &, 003 \\
AYDÇ & 164 & 19,09 & 5,70 & 164 & 15,58 & 5,35 & 5,724 &, 000 \\
YASEÇ & 164 & 20,27 & 8,16 & 164 & 17,83 & 9,69 & 2,322 &, 021 \\
AYSEÇ & 164 & 19,16 & 5,58 & 164 & 16,72 & 4,97 & 4,167 &, 000 \\
YASOEÇ & 164 & 19,03 & 8,31 & 164 & 15,89 & 6,00 & 3,919 &, 000 \\
AYSOEÇ & 164 & 18,48 & 5,29 & 164 & 15,36 & 4,44 & 5,761 &, 000 \\
SOSYÇ & 164 & 19,20 & 7,68 & 164 & 16,90 & 6,34 & 2,945 &, 003
\end{tabular}




\begin{tabular}{|c|c|c|c|c|c|c|c|c|}
\hline \multirow[b]{2}{*}{ SASYÇ } & \multicolumn{7}{|c|}{ Başaran, M./ Pamukkale Üniversitesi Eğitim Fakültesi Dergisi, 52, 86-118, 2021} & \multirow{2}{*}{$\begin{array}{l}103 \\
, 000\end{array}$} \\
\hline & 164 & 18,45 & 4,20 & 164 & 16,00 & 5,07 & 4,739 & \\
\hline SYTD & 164 & 15,80 & 5,82 & 164 & 14,18 & 4,43 & 2,826 & ,005 \\
\hline SYD & 164 & 15,36 & 4,43 & 164 & 13,00 & 2,54 & 5,882 & 000 \\
\hline
\end{tabular}

Not: YADÇ: Yukarıdan aşağıya çizilmiş dik çizgi, AYDÇ: Aşağıdan yukarıya çizilmiş dik çizgi, YASEÇ: Yukarıdan aşağıya çizilmiş sağa eğik çizgi, AYSEÇ: Aşağıdan yukarıdan çizilmiş sağa eğik çizgi, YASOEÇ: Yukarıdan aşağıya çizilmiş sola eğik çizgi, AYSOEÇ: Aşağıdan yukarıdan çizilmiş sola eğik çizgi, SOSYÇ: Soldan sağa çizilmiş yatay çizgi, SASYÇ: Sağdan sola çizilmiş yatay çizgi, SYTD: Saat yönünün tersine çizilmiş daire, SYD: Saat yönünde çizilmiş daire

Tablo 5'te satır üzerinde bulunan kılavuz çizgilerin çizgi çizme hızı üzerindeki etkisi görülmektedir. Tabloya göre kılavuz çizgilerin hangi yöne doğru çizilirse çizilsin dik, eğik ve yatay çizgileri çizme ve daire çizme hızı üzerinde anlamlı bir etkisi vardır $(\mathrm{p}<.05)$. Bu sonuç ilgili betimsel verilerle beraber incelendiğinde kılavuz çizgilerinin çizme yönü ne olursa olsun, harf çizgilerini çizme hızını düşürdüğü görülmektedir. Ancak bu bulgu okunurken tabloda bulunan saniye cinsinden değerlerin toplamda 10 çizgiyi çizmek için harcanan zaman olduğu unutulmamalıdır. Diğer bir deyişle aradaki farkın sebebi, çizgileri çizmek için harcanan zaman değildir; bir çizgiyi çektikten sonra kalemin kaldırılıp diğer çizgiyi çizmek için kâğıtta uygun yere konması için harcanan zamandır.

Tablo 6. Kılavuz Çizgileri ile Çizgi Niteliği Arasındaki iliş̧i

\begin{tabular}{lcccccccc}
\hline \multirow{2}{*}{ Değişken } & \multicolumn{9}{c}{ Kılavuz çizgisi var } & \multicolumn{7}{c}{ Kılavuz çizgisi yok } & \multirow{2}{*}{$\mathrm{t}$} & $\mathrm{p}$ \\
\cline { 2 - 7 } & $\mathrm{N}$ & $\mathrm{X}$ & $\mathrm{SS}$ & $\mathrm{N}$ & $\mathrm{X}$ & $\mathrm{SS}$ & & \\
\hline YADÇ & 164 & 2,45 &, 70 & 164 & 2,22 &, 72 & 2,928 &, 004 \\
AYDÇ & 164 & 2,25 &, 81 & 164 & 2,03 &, 83 & 1,988 &, 041 \\
YASEÇ & 164 & 2,41 &, 76 & 164 & 2,00 &, 77 & 4,811 &, 000 \\
AYSEÇ & 164 & 2,20 &, 85 & 164 & 1,89 &, 84 & 3,307 &, 001 \\
YASOEÇ & 164 & 2,35 &, 69 & 164 & 2,03 &, 72 & 4,171 &, 000 \\
AYSOEÇ & 164 & 2,29 &, 71 & 164 & 2,03 &, 77 & 3,241 &, 001 \\
SOSYÇ & 164 & 2,38 &, 64 & 164 & 1,99 &, 77 & 4,955 &, 000 \\
SASYÇ & 164 & 2,26 &, 76 & 164 & 1,87 &, 78 & 4,646 &, 000 \\
SYTD & 164 & 2,09 &, 77 & 164 & 1,81 &, 70 & 3,361 &, 001 \\
SYD & 164 & 1,76 &, 73 & 164 & 1,75 &, 83 & 1,403 &, 173 \\
\hline
\end{tabular}

Not: YADÇ: Yukarıdan aşağıya çizilmiş dik çizgi, AYDÇ: Aşağıdan yukarıya çizilmiş dik çizgi, YASEÇ: Yukarıdan aşağıya çizilmiş sağa eğik çizgi, AYSEÇ: Aşağıdan yukarıdan çizilmiş sağa eğik çizgi, YASOEÇ: Yukarıdan aşağıya çizilmiş sola eğik çizgi, AYSOEÇ: Aşağıdan yukarıdan çizilmiş sola eğik çizgi, SOSYÇ: Soldan sağa çizilmiş yatay çizgi, SASYÇ: Sağdan sola çizilmiş yatay çizgi, SYTD: Saat yönünün tersine çizilmiş daire, SYD: Saat yönünde çizilmiş daire 
Tablo 6'da satır üzerinde bulunan kılavuz çizgilerinin, çizgilerin niteliği üzerindeki etkisi görülmektedir. Tabloya göre kılavuz çizgilerinin hangi yöne doğru çizilirse çizilsin dik, eğik ve yatay çizgiler ile saat yönünün tersine doğru çizilen dairenin niteliği üzerinde anlamlı bir etkisi vardır $(\mathrm{p}<.05)$. Ancak saat yönünde çizilen daire üzerinde anlamlı bir etkisi bulunmamaktadır ( $\mathrm{p}>.05)$. Bu sonuç, ilgili betimsel verilerle beraber incelendiğinde kılavuz çizgilerin saat yönünde çizilen daire hariç çizme yönü ne olursa olsun harf çizgilerinin niteliğini artırdığı şeklinde yorumlanabilir.

Tablo 7. Sınıf Düzeyi ile Çizgi Çizme Hızı ve Çizgi Niteliği Arasındaki İlişki

\begin{tabular}{lcccccccccc}
\hline Sinıf & & & YAS & AYS & YASO & AYSO & SOS & SAS & & \\
düzeyi & YAD & AYD & E & E & E & E & Y & Y & SYTD & SYD \\
\hline Hiz &,$- 219^{* *}$ &,$- 279^{* *}$ &,- 099 &,$- 181^{*}$ &,$- 333^{* *}$ &,$- 178^{*}$ &,$- 179^{*}$ &,$- 200^{*}$ &,$- 309^{* *}$ &, 079 \\
Nitelik &, 001 &, 035 &, 108 &, 011 &, 153 &, 003 &, 100 &, 054 &, 142 &, 008 \\
\hline
\end{tabular}

$* \mathrm{p}<.05, * * \mathrm{p}<.01$

Tablo 7'de sınıf düzeyi ile çizgi çizme hızı ve çizgi niteliği arasındaki ilişki gösterilmektedir. Tabloya göre dik çizgiyi yukarıdan aşağıyla çizmek ve saat yönünde daire çizmek hariç, tüm çizgileri çizme için harcanan zaman ile sınıf düzeyi arasında negatif yönlü anlamlı bir ilişki söz konusudur $(\mathrm{p}<.05)$. Bu sonuç, -saat yönünde daire ve yukarıdan aşağıya sağa eğik çizgi çizme hariç- sınıf düzeyi yükseldikçe öğrencilerin harf çizgilerini daha hızlı çektikleri şeklinde yorumlanabilir. Sınıf düzeyi ile çizgilerin niteliği arasında ise anlamlı bir ilişki bulunamamıştır ( $\mathrm{p}>$.05).

Tablo 8. Çizgi Çizme Hızı İle Çizgilerin Niteliği Arasındaki İlişki

\begin{tabular}{llllll}
\hline Çizgi & & & & \\
çizme & & & & \\
hızı/çizgi & & & & \\
niteliği & YAD & AYDÇ & YASE AYSE YASOE AYSOE SOSY SASY SYTD SYD \\
\hline YADÇ &, $283^{* *}$ & & & \\
AYDÇ &, 054
\end{tabular}

YASEÇ

AYSEÇ

, 080

YASOEÇ

AYSOEÇ

, 052

SOSYÇ 
$* \mathrm{p}<.05, * * \mathrm{p}<.01$

Not: YADÇ: Yukarıdan aşağıya çizilmiş dik çizgi, AYDÇ: Aşağıdan yukarıya çizilmiş dik çizgi, YASEÇ: Yukarıdan aşağıya çizilmiş sağa eğik çizgi, AYSEÇ: Aşağıdan yukarıdan çizilmiş sağa eğik çizgi, YASOEÇ: Yukarıdan aşağıya çizilmiş sola eğik çizgi, AYSOEÇ: Aşağıdan yukarıdan çizilmiş sola eğik çizgi, SOSYÇ: Soldan sağa çizilmiş yatay çizgi, SASYÇ: Sağdan sola çizilmiş yatay çizgi, SYTD: Saat yönünün tersine çizilmiş daire, SYD: Saat yönünde çizilmiş daire

Tablo 8'de çizgilerin niteliği ile çizgileri çizme hızı arasındaki ilişkiye ait veriler görülmektedir. Tabloya göre yukarıdan aşağı doğru çekilen dik çizgi ile saat yönünün tersine çizilen dairenin niteliği ve yine bu çizgileri çizmek için harcanan zaman arasında pozitif yönlü zayıf bir ilişki söz konusudur $(\mathrm{p}<.05)$. Bu bulgu yukarıdan aşağı doğru çekilen dik çizgi ile saat yönünün tersine çizilen daireyi çizmek için harcanan zaman arttıkça (bu çizgileri daha yavaş çizdikçe) bu çizgilerin niteliğinin de artacağı şeklinde yorumlanabilir. Tablo incelendiğinde tüm korelasyon katsayılarının anlamlı olmasa da pozitif yönlü olduğu da görülmektedir. Diğer bir deyişle çizgi niteliğini artırmak çizme hızına da dikkat edilmesi gerektiği söylenebilir.

\section{Tartışma ve Sonuç}

Araştırmanın birinci alt problemi "Çizgi çizme yönü ile çizme hızı ve çizgi niteliği arasında bir ilişki var mıdır?” şeklinde ifade edilmiştir. Bu alt probleme ilişkin bulgulara göre 1, 2, 3, ve 4. sınıf düzeyinde dik, eğik, yatay çizgiler ile daire çizmede, çizgi çekim yönü ile çizginin çekim süresi arasında anlamlı bir ilişki bulunmamaktadır. Ancak betimsel verilere göre tüm sınıf seviyelerinde dik, sağa ve sola eğik çizgiler yukarıdan aşağıya; yatay çizgiler soldan sağa daha hızlı çekilmektedir. Daire diğer çizgilere göre daha hızlı çizilmektedir. Ayrıca dairenin çizim yönü ile çizim hızı arasındaki ilişki diğer çizgilere göre daha düşüktür.

Araştırma bulgularına göre çizgi niteliği üzerinde, çizme hızı, çizgi çizme yönüne göre daha etkilidir. Diğer bir deyişle öğrenciler çizgileri daha yavaş çizdiğinde çizgilerin niteliği artmaktadır. Ayrıca öğrenciler dik ve eğik çizgileri yukarıdan aşağıya, yatay çizgiyi soldan sağa ve daireyi saat yönünün tersine çizdiklerinde, çizgiler daha nitelikli olmaktadır. 1-4 sınıf düzeyinde daire diğer çizgilere göre daha düşük niteliktedir. Diğer bir deyişle tüm sınıf seviyelerinde en hızlı daire çizilmektedir ancak niteliği en düşük olan şekil yine dairedir. Bu bulgular öğrencilerin dik temel harflerle yazarken dik ve eğik harf çizgilerini 
yukarıdan aşağıya; yatay çizgileri soldan sağa ve daireyi de saat yönünün tersine çizmelerinin yazma hızını ve niteliğini artırabileceği şeklinde yorumlanabilir.

Bu sonuçların ortaya çıkmasında kavramsal çerçevede anlatılan ve yazma esnasında aktif olarak kullanılan el kaslarının çalışma prensiplerinin etkili olduğu söylenebilir. Yazma esnasında etkin şekilde kullanılan baş, işaret ve orta parmă̆ içe doğru büken kasların, dışa doğru açan kaslara göre hem daha hassas hem de daha güçlü olduğu düşündüğünde, harf çizgilerini yukarıdan aşă̆lya doğru çizmenin hem çizgi niteliğini hem de çizme hızını arttırması beklendik bir sonuçtur.

Araştırma sonucu elde edilen bulgular ve buraya kadar yazma ile ilgili kas ve sinir sistemi hakkında verilen bilgilerden hareketle harf çizgilerinin öğretilmesi sürecinde şu ilkelere dikkat edilmesi gerektiği söylenebilir:

- Yazarken elini içe doğru büken (hilalleme), elini dişa doğru büken (kalemin silgi olan tarafının dış tarafı göstermesi) veya kalemi başparmağının ucu ile değil yanıyla tutan bir öğrencinin önkol kaslarını aktif/baskın olarak kullandığı; yazmayı kaba motor hareketlerle yapmaya çalıştığı ve bu kaslarını gereğinden fazla yorduğu söylenebilir. Oysa bu kaslar büyük motor beceriler için uygundur ve eli uygun bir şekilde tutmak amacıyla az miktarda kullanılmalıdır.

- Bel, sirt, omuz, kol ve önkolda bulunan kaslar, yazmada aktif olarak kullanılmasa da bu kaslar eli ve vücudu uygun pozisyonda tutmak için kullanıldığından yazı hızı ve okunaklılığı üzerinde dolaylı etkiye sahiptir.

- Harf çizgilerini oluşturma en çok başparmağı sonra işaret ve orta parmağı hareket ettiren kaslara bağlıdır. Başparmak, diğer parmaklara göre çok sayıda büyük ve küçük kas aracılığıyla hareket ettirilmekte; ayrıca elde ve önkolda sadece bu parmağı oldukça hassas şekilde hareket ettiren kaslar yer almakta; motor kortekste ise bu parmağın hareketinden sorumlu oldukça büyük bir alan bulunmaktadır. Bu nedenle elle yapılan çoğu işte olduğu gibi yazmada da başparmak baskın şekilde kullanılmalıdır.

- Baş, işaret ve orta parmak anatomisi ayrıca incelendiğinde bu parmakları avuç içine doğru büken kasların, dışa doğru açan kaslara göre çok daha güçlü olduğu dolayısıyla bu parmakların içe doğru yaptığı hareketleri daha güçlü, kolay ve hassas yaptığı görülmektedir.

- Araştırmadan elde edilen sonuçlar ilgili literatür aracılığıyla tartışıldığında, çizgileri yukardan aşağıya, sağdan sola ve dairenin de saat yönünün tersine çizilmesinin el 
anatomisine daha uygun olduğu; çizme hızı ve niteliğini olumlu etkilediği söylenebilir.

$\mathrm{Bu}$ sonuçlardan hareketle, ana sınıflarında yapılan yazmaya hazırlık etkinlikleri ile ilkokul birinci sınıflarda yapılan çizgi ve harf çalışmalarında öğretmenlerin,

- Öğrencilerin dik ve eğik çizgileri yukarıdan aşağıya; yatay çizgileri soldan sağa ve daireyi ise saat yönünün tersine çizmelerine dikkat etmesi,

- Öğrencilere doğru oturuş, kağıdı konumlandırma ve boştaki eli konumlandırma gibi yazmanın ergonomisine etki eden diğer davranışları da öğretmesi,

- Kalemi doğru tutuşu öğretmesi,

- Yazarken başparmağın asıl işlevinin kalem hareket ettirme; orta parmağın kalemin yükünü taşıma ve işaret parmağının ise kalemi sabitlemek olduğu anlatmas1,

- Harf çizgilerinin niteliğini arttırmak için öğrencilerin yazma hızına da dikkat etmesi, harf çizgilerinin niteliği düşük öğrencilerin daha yavaş yazmasını istemesi gerektiği söylenebilir.

Araştırmanın ikinci alt problemi "Kılavuz çizgiler ile çizme hızı ve çizgi niteliği arasında bir ilişki var mıdır?” şeklinde ifade edilmiştir. Diğer bir deyişle bu araştırmada harfleri yazmada zaman alan diğer bir etken olan kalemin ucunun kaldırılıp uygun yere götürülmesinin yazma hızı ve çizgi niteliği üzerindeki etkisine de bakılmıştır. Bu uygulama sonucunda çizme yönü ne olursa olsun k1lavuz çizgilerle belirlenen alan içerisine çizgi çizmenin, çizme hızını düşürdüğü görülmüştür. Aslında tek bir çizgiyi belirlenen alan içine, belirlenen noktadan başlayarak çizmeyle istediği yerden başlayarak çizme hızının aynıdır. Burada gözlenen farkın kaynağı kalemin ucunun kaldırılıp uygun noktaya konması için harcanan zamanın, yazma hızı üzerinde oldukça etkili olmasıdır. Bu bulgular dik temel harflerin yazımında kalemin ucunun kaldırılıp uygun noktaya konmasının yazma hızı üzerinde etkili olduğunu söyleyen araştırmaların (Alston ve Taylor, 1987; Amudson, 2001; Başaran ve Karatay, 2005; Erdoğan, 2012; Güneş, 2017) sonuçlarıyla da örtüşmektedir. Ayrıca yatay çizgileri soldan sağa doğru çizmenin sağdan sola doğru çizmekten daha hızlı olmasının nedeni de bu bulgu olabilir. Zira yatay çizgi yazma yönüne doğru (soldan-sağa) çekildiğinde kalemin ucu kaldırılıp çok yakın bir noktaya götürülmektedir. Yatay çizgi, yazma yönünün tersine (sağdan-sola) çizildiğinde ise kalemin ucu nispeten daha uzak bir noktaya götürüleceğinden yazma hızı düşmektedir. 
Araştırmada kılavuz çizgilerle ayrılan bölgeye çizmenin her ne kadar çizgi çizme hızını düşürse de çizgi niteliğini arttırdığı sonucuna ulaşılmıştır. Yine bu araştırmanın sonuçlarına göre çizgi çizme hızı ile çizgi niteliği arasında gözlenen ilişki oldukça düşük düzeydedir. Buradan hareketle kılavuz çizgiler yardımıyla çizilen çizgilerin niteliğinin artmasını sağlayan temel etken, belirlenmiş alanlara çizgilerin daha yavaş çizilmesi değil; öğrencilerin çizerken kılavuz çizgileri referans alması olabilir. Bu bulgudan hareketle özellikle ilkokul birinci sınıfların yazı defterlerinde kullanılan kılavuz çizgi (bkz. Şekil 10.) uygulamasının yerinde olduğu ve öğretmenlerin, öğrencileri yazarken bu çizgileri referans alması hususunda uyarmaları gerektiği söylenebilir.

\section{Şekil 11. Kılavuz çizgili yazı defteri satırları}

Araştırmada cevabı aranan üçüncü alt problem ise "Cinsiyet ile çizme hızı ve çizgi niteliği arasında bir ilişki var mıdır?" şeklinde ifade edilmiş olup bu probleme ilişkin bulgur ise şunlardır: Kız öğrenciler, erkek öğrencilere göre tüm çizgileri daha hızlı çizmektedir. Ancak kız ve erkek öğrencilerin çizgilerinin nitelikleri arasında belirgin bir fark yoktur. $\mathrm{Bu}$ sonuçlar, kız öğrencilerin erkek öğrencilerden daha hızlı yazabileceği ancak yazının okunabilirliği ve estetik olması üzerinde cinsiyetin etkisinin bulunmadığı şeklinde yorumlanabilir. Bu bulgu yazının akıcılığı veya okunaklılığı üzerinde cinsiyetin etkisini araştıran ve kız öğrencilerin erkek öğrencilere göre daha hızlı yazdıkları sonucuna ulaşan çalışmaların (Coşkun ve Coşkun, 2012; Cohen, 1997; Duran ve Akyol, 2010; Höbek ve Taşkaya, 2018) bulgularıyla uyum göstermektedir. Kız öğrencilerin erkek öğrencilerden daha hızlı çizgi çizebilmeleri, kız öğrencilerin erkek öğrencilere göre ince motor becerilerin daha gelişmiş olmasından kaynaklanabilir. Ayrıca yazmanın, odaklanma ve uzun süre hareketsiz kalmayı gerektirmesi ve kız öğrencilere göre daha hareketli olan erkek öğrencilerin yazma esnasında daha fazla zorlaması da bu sonuçların ortaya çıkmasında etkili olabilir (Erden ve Akman, 1998). Yazma eğitiminde daha çok kız öğrencilerin dikkatini çekecek materyallerin (romantik, duygusal, ders vermeye odaklı vb.) seçilmiş olması da (Güneş, 2016) bu sonucun diğer bir nedeni olarak düşünülebilir.

$\mathrm{Bu}$ bulgulardan hareketle ana sınıfı ve sınıf öğretmenlerine yazma etkinlikleri yapılırken erkek öğrencilerin yazma problemlerinin gelişim özelliklerinden kaynaklanabileceğini unutmamaları ayrıca kısa aralıklarla öğrencileri dinlendirecek veya enerjilerini boşaltabilecek uygulamalar yapmaları önerilebilir. 
Araştırmanın dördüncü alt problemi ise "Sınıf düzeyi ile çizme hızı ve çizgi niteliği arasında bir ilişki var mıdır?" şeklinde ifade edilmiştir. Elde edilen sonuçlara göre sınıf düzeyi arttıkça yön fark etmeksizin harf çizgilerinin daha hızlı çekildiği söylenebilir. Bu bulgu sınıf düzeyi arttıkça yazma hızının da artacağını söyleyen ilgili literatürle (Arslan ve Bağcı, 2017; Arslan ve Ilgın, 2010; Çevik, 2006; Doğan, 2007; Duran, 2011; Vlachos ve Bonoti, 2006) uyumludur. Sınıf düzeyi ile çizgilerin niteliği arasındaki ilişkiye bakıldığında ise bu iki değişken arasında anlamlı ilişkinin olmadığı görülmüştür. Bu bulgu, öğrencilerin çizgilerinin niteliğinin ilk sınıflarda nasılsa sonraki sınıflarda da aynı olacağını göstermektedir.

$\mathrm{Bu}$ bulgulardan hareketle yazma eğitiminde birinci sınıfın, diğer sınıflara göre daha önemli olduğu; sonraki sınıflarda da kullanılan kalem tutma, doğru oturma, harfleri doğru yazma, harf çizgilerini doğru çizme, hızlı, güzel ve okunaklı yazma gibi yazma için çok önemli olan pek çok becerinin birinci sınıfta kazandırılması gerektiği söylenebilir. Çünkü bu beceriler birinci sınıfta kazandırılamaz veya öğrenci yazmanın ergonomisiyle ilgili yanlış davranışlar öğrenirse, bu davranışların düzeltilmesi veya doğru davranışların öğretilmesi sonraki sınıflarda çok daha zor olmaktadır (Başaran, 2006; Beaty ve Çetin, 2014; Bratt, 2007; Graham vd., 2008; Erden ve Altun, 2014; Y1ldız vd., 2009; Y1lmaz ve McMullan, 2010).

Etik Kurul İzin Bilgisi: Bu çalışmanın verileri 2019 yılında toplandığından etik kurul izni alınmamıştır.

Yazar Çıkar Çatışması Bilgisi: Çalışma kapsamında herhangi bir kişisel ve finansal çıkar çatışması bulunmamaktadır.

Yazar Katkısı: Makalenin hazırlanması ve düzeltilmesine ilişkin katkı ilgili yazar tarafindan gerçekleştirilmiştir 


\section{Kaynakça}

Ak, B. D. ve Kesik, F. S. (2014). Yabancı dil olarak Türkçe öğrenen Balkanlı öğrencilerin yazılı anlatımda yaptıkları hatalar üzerine tespitler. Uluslararası Dil ve Edebiyat Ë̆itimi Dergisi, 10, 100-119.

Akyol, H. (2012). Türkçe ilk okuma yazma öğretimi (5. Baskı). Ankara: Pegem A Yayınc1lik.

Alston, J. \& Taylor, J. (1987), Handwriting: Theory, research and practice. New York: Nichols Publishing.

Alston, J. (1986). The effects of pencil barrel shape and pupil barrel preference on hold or grip in 8-year-old pupils. British Journal of Occupational Therapy, 49(2), 42-44.

Amudson S. J. (2001). Prewriting and handwriting skills, occupational therapy for children. St. Louis, Missouri: Mosby.

Amundson, S. J. (1995). Eveluation children's handwriting. USA: O.T. Kids.

Arı, G. (2010). Altıncı ve yedinci sınıf öğrencilerinin yazdığı hikâye edici metinlerin değerlendirilmesi. $T \ddot{U} B A R, 15(27)$, 43-75.

Arseven, C. (1992). Yazı. Sanat Ansiklopedisi V. İstanbul: Milli eğitim basımevi.

Arslan, D. ve Bağcı, H. (2017). İlköğretim öğrencilerinin (2.-7. sınıf ) yazı hızı: kesit çalışması. Uluslararası Sosyal Araştırmalar Dergisi, 10(50), 451-461.

Arslan, D. ve Ilgın, H. (2010). Öğretmen ve öğrencilerin bitişik eğik yazı ile ilgili görüşleri. İn̈nü Üniversitesi Ĕ̈itim Fakültesi Dergisi, 11( 2), 69-92.

Ayrancı, B. (2018). Eğitim fakültesi öğrencilerinin yazılı anlatım dersi uygulamalarında alanlarına özgü etkinlik oluşturma çalışmaları. Zeıtschrıft Für Dıe Welt Der Türken, 10(1), 143-157.

Baldini, M. (2000). İletişim tarihi. İstanbul: Avcılol Basım Yayın.

Bara, F. \& Morin, M. F. (2013). Does the handwriting style learned in first grade determine the style used in the fourth and fifth grades and influence handwriting speed and quality? A comparison between french and quebec children. Psychology in the Schools, 50(6), 601-617.

Barry P. S., \& Caffinere J. Y. (1981).Physiology of flexion of the fingers. The hand 377-88. (Ed. Tubiana R) Philadelphia: Saunders.

Başaran, M. (2006). “İlkokuma yazma öğretimi sürecinde öğrencilerin yaptıkları yazım yanlışları. Ulusal Sınıf Öğretmenliği Kongresi Gazi Üniversitesi, Bildiri Kitabı 1.Cilt, Ankara: Kök Yayıncılık. 
Başaran, M. ve Akyol, H. (2019). Dördüncü sınıf öğrencilerinin kalem tutuşlarının ergonomik unsurlar açısından incelenmesi. Okuma Yazma Eğitimi Araştırmaları, $7(1), 1-14$.

Başaran, M. ve Karatay, H. (2005). Eğik el yazısı öğretimi. Millî Eğitim Dergisi, 33(168), 27-34.

Başaran, M. (2006). İlkokuma-Yazma öğretimi sürecinde öğrencilerin yaptıkları yazım yanlışlıkları. Ulusal Sınıf Öğretmenliği Kongresi. (14-16 Nisan 2006). Ankara: Gazi Üniversitesi.

Bayraktar, Ö. (2006). İlköğretim birinci sınıf öğrencilerinin bitişik ĕ̆ik yazıda yaptıkları hatalar. (Yayımlanmamış yüksek lisans tezi). Gazi Üniversitesi Eğitim Bilimleri Enstitüsü, Ankara.

Baştuğ, M. ve Demirtaş, G. (2016). Her ses/harf için özel uygulamalı ilkokuma ve yazma ögretim el kitabı. Ankara: Pegem Akademi Yayınları.

Blöte, W. A., \& Hamstra B. L. (1991). A longitudinal study on structure of handwriting. Perceptual Motor Skills, 72(1), 983-994.

Baştürk, M. (2004). Dil edinim kuramları ve Türkçenin ana dili olarak edinimi. Ankara: PegemA Yayınc1lık.

Beaty, J. J. ve Bratt, L. (2007). Early literacy in preschool and kindergarten a multicultural perspective (2th ed.). New Jersey: Pearson Education Inc.

Biant, L. C. (2016). Elbow and forearm. Section 6: Pectoral girdle and upper limb (ed. Rolfe Birch). Gray's Anatomy (41. Bask1), (ed. Susan Standring). London: Elsevier, 837862.

Binbaşığlu, C. (2004). Illkokuma ve yazma ögretimi, Ankara: Nobel Yayın Dağıtım.

Brink, A. O., \& Jacobs, A. B. (2011). Kinesthetic sensitivity and related measures of hand sensitivity in children with nonproficient handwriting. Pediatric Physical Therapy, 23(1), 88-94.

Butgel, T. S., Gözü, Ö. ve Özen, G. (2016). Nitel ve nicel araştırma yöntemlerinin bir arada kullanılması "karma araştırma yöntemi” Anadolu Üniversitesi Iletişim Bilimleri Fakültesi Uluslararası Hakemli Dergisi. 24(2), 106-112.

Clair, K. (1999). A typographic workbook. Canada: John Wiley ve Sons, Inc.

Cohen, M. R. (1997). Individual and sex differences in speed of handwriting among high school students. Perceptual and Motor Skills, 84(1), 1428-1430.

Coşkun, E. ve Coşkun, H. (2012). İlköğretim öğrencileri ile sınıf ve Türkçe öğretmenlerinin bitişik eğik yazı başarı düzeylerinin değerlendirilmesi. GUJGEF, 32(3), 761-776. 
Cömert, Ö. ve Aktaş, M. (2011). Matematik eğitiminde kullanılan simetrinin uygulandığı bir şeklin Türkçe ve ilköğretim matematik öğretmenliği 1. sınıf öğrencilerinin yazma becerilerine etkisi. Zeitschrift Für Die Welt Der Türken, 3(2), 99-111.

Creswell, J. W. (2012). Educational research: planning, conducting, and evaluating quantitative and qualitative research (4th ed.). Boston: Pearson Education Inc.

Çetin Ş. Ö. (2014). Okul öncesi dönemindeki çocukların yazı farkındalığı ve yazmaya hazırlık becerilerinin incelenmesi. Kuramsal Eğitimbilim Dergisi, 7(3) 342-360.

Çerçi, A. ve Bardakçı, M. (2016). Yabancı dil olarak Türkçe öğrenen öğrencilerin yazılı anlatımlarına yönelik yanlış çözümlemesi. Gaziantep University Journal of Social Sciences, 15(2), 695-715.

Çevik, S. O. (2006). Birinci sınıf öğretmenlerinin ilkokuma yazma ögrretiminde ses temelli cümle yöntemine ilişkin görüşleri (Bursa İli Örneği). (Yayımlanmamış yüksek lisans tezi). Anadolu Üniversitesi Eğitim Bilimleri Enstitüsü, Eskişehir.

Dennis, J. L., \& Swinth, Y. (2001). Pencil grasp and children's handwriting legibility during different length writing tasks. American Journal of Occupational Therapy, 55, 175183.

Doğan, B. (2007). Denizli ili ilköğretim okullarında çalışan birinci sınıf öğretmenlerinin ses temelli cümle yöntemine ilişkin görüşleri. AİBÜ Eğitim Fakültesi Dergisi, 7(1), 7990.

Dodd, B., \& Carr, A. (2003). Young children's letter-sound knowledge. Language, Speech and Hearing Services in Scholols, 34, 128-137.

Donoughue, C. (2009). Yazının öyküsü. İstanbul: Türkiye İş Bankası Yayınları.

Duran, E. (2011). Bitişik Eğik yazı harflerinin yazım şekillerine ilişkin öğretmen görüşleri. Ondokuz, Mayıs Üniversitesi Eğitim Fakültesi Dergisi, 30(2), 55-69.

Duran, E. ve Akyol, H. (2010). Bitişik eğik yazı öğretimi çalışmalarının çeşitli değişkenler açısından incelenmesi. Türk Ĕ̈itim Bilimleri Dergisi, 8(4), 817-838.

Ellis H. (1992) Clinical anatomy, 207-215. London: Blackwell Scientific Publications,

Erdoğan, T. (2012). İlköğretim birinci sınıf öğrencilerinin bitişik eğik yazı yazma gelişimlerinin incelenmesi. Eğitim ve Bilim, 37(165), 2-11.

Erden, M. ve Akman, Y. (1998). Gelişim, öğrenme-öğretme. Ankara: Arkadaş Yayınları.

Erden T. F. ve Altun D. (2014). Sınıf öğretmenlerinin okul öncesi eğitim ve ilköğretime geçiş süreci hakkındaki görüşlerinin incelenmesi. İlköğretim Online, 13(2), 481-502.

Erdoğan, T. (2012). İlköğretim birinci sınıf öğrencilerinin bitişik eğik yazı yazma gelişimlerinin incelenmesi. Eğitim ve Bilim, 37(165) 93-103. 
Fatemeh, H., Hadi, B., Fatemeh, B., Mozhgan, F., \& Masood, S. (2008). Handwriting difficulties: Introducing an instrument, Iranian Rehabilitation Journal, 6(7-8), 39-46.

Feder, K. P., \& Majnemer, A. (2007). Handwiritng development, competency and intervention, Developmental Medicine \& Child Neurology, 49(1), 312-317.

Fitzgerald, T. (2012). Documents and documentary analysis. In A. R. J. Briggs, M. Coleman, ve M. Morrison (Eds.), Reseach methods in educational leadership ve management (296-308). London: Sage.

Iş11, B. (1991). Ergonomi. İzmit: Yıldız Ün. Yayınları.

Graham, S., Harris K. R., Mason, L., Fink-Chorzempa, B., Moran, S., \&Saddler, B. (2008). How do primary grade teachers teach handwriting? A National Survey. Reading and Writing,21(1-2),49-69.

Graham, S., Struck, M., Santoro, J., \& Bernınger, V. W. (2006). Dimensions of good and poor handwriting legibilityin first and second graders: motor programs, visual-spatial arrangement, and letter formation parameter setting. Developmental Neuropsychology, 29(1), 43-60.

Graham, S., Weintraub, N., Berninger, V.W., \& Schafer, W. (1998). Development of handwriting speed and legibility in grades 1-9. Journal of Educational Research, 92(1),42-51.

Güler C. (2003). Ergonomiye giriş. Ankara: Ankara Tabip Odası.

Güneş, F. (2016). Türkçe öğretimi yaklaşımlar ve modeller. Ankara: Pegem Akademi.

Güneş, F. (2017). Bitişik eğik ve dik temel yazı savaşları. Sınırsız Eğitim ve Araştırma Dergisi, 2(3), 1-20.

Güneyli, A. (2006). Kitap incelemesi. İlkögrretim Online, 5(2), 50.

Gürcan, S. ve Adıyaman S. (2008). Elin anatomisi ve kineziyolojisi. Türkiye Klinikleri J PMveR-Special Topics. (El Rehabilitasyonu Özel Sayıs1), 1(1),1-9.

Halıcı, B. (2019). Kalem şeklinin ilkokul ögrencilerinin yazma hızına etkisinin incelenmesi. (Yayınlanmamış yüksek lisans tezi). Yozgat Bozok Üniversitesi Sosyal Bilimler Enstitüsü, Yozgat.

Hamstra B. L., \& Blöte, W. A. (1993). A longitudinal study on dysgraphic handwriting in primary school. Journal of Learning Disabilities, 26(10), 689- 699.

Hamzadayı, E. ve Çetinkaya, G. (2011). Yazılı anlatımı düzenlemede akran dönütleri: dönüt türleri, öğrenci algıları. AİB̈̈ Ĕ̆itim Fakültesi Dergisi, 11(1), 147-165.

Havens M. C. (2002). Emergent writing in precshool (Yayınlanmamış doktora tezi). The State University of New Jersey, New Jersey. 
Höbek G ve Taşkaya S. M. (2018). İlkokul öğrencilerinin yazma hızının belirlenmesi. Hitit Üniversitesi Sosyal Bilimler Enstitüsü Dergisi, 11(3), 2433-2445.

Kahraman G. (2001). Bilek, el ve parmakları hareket ettiren kas ve tendon yapıları. El ve El bileği Cerrahi Anatomi Mezuniyet Sonrası Eğitim Kurs Kitabı. İstanbul: Cerrahpaşa.

Karasar, N. (2013). Bilimsel araştırma yöntemi (25. bs.). Ankara: Nobel yayın dağıtım.

Kavak, S. T. ve Bumin, G. (2009). The effects of pencil grip posture and different desk design on handwriting performance in children with hemiplegic cerebral palsy. Journal de Pediatria, 85(4), 346-352.

Kırbaş, A. ve Orhan, S. (2011). Görsel materyallerle desteklenmiş yazma çalışmalarının öğrencilerin yazma becerilerini geliştirmeye etkisi. Turkish Studies, 6(4), 705-714.

Kırmızı, F. S. ve Ünal, E. (2016). İlk okuma yazma öğretimi. Ankara: Anı Yayıncılık.

Koziatek, S. M., \& Powell, N. J. (2003). Pencil grips, legibility and speed of fourth-graders' writing in cursive. American Journal of Occupational Therapy, 57(3), 284-288.

Lambert S. M. (2016). Shoulder girdle and arm. Section 6: Pectoral girdle and upper limb (ed. Rolfe Birch). Gray's anatomy (41. Bask1), (ed. Susan Standring). London: Elsevier, 797-837.

Lubahn, J. D. (1996). Hand evaluation. Regional review courses in hand surgery (Courses Book). Portland, Oregon, 1-13.

MEB, (2006). Türkçe dersi öğretim programı. Ankara: MEB basımevi.

MEB, (2010). Türkçe dersi ögretim programı. Ankara: MEB basımevi.

MEB, (2015). Türkçe dersi ögretim programı. Ankara: MEB basımevi.

MEB, (2018). Türkçe dersi öğretim programı. Ankara: MEB basımevi.

MEB, (2019). Türkçe dersi öğretim programı. Ankara: MEB basımevi.

Medwell, J., \& Wray, D. (2007). Handwriting: what do we know and what do we need to know? Literacy, 41(1), 10-15.

Memiş, A. D., Harmankaya, T. (2012). İlköğretim okulu 1. sınıf öğrencilerinin bitişik eğik el yazısı hataları ile görsel algı düzeylerinin incelenmesi. Dicle Üniversitesi Ziya Gökalp Ĕgitim Fakültesi Dergisi, 19,136-150.

Overvelde, A., \& Hulstijn, W. (2011). Handwriting development in grade 2 and 3 primary school children with normal, at risk, or dsygraphic characteristics. Research in Developmental Disabilities, 32(1), 540-548.

Palmis, S., Velay, J. L., Danna, J., \& Longcamp, M. (2017). Motor control of handwriting in the developing brain: A review. Cognitive Neuropsychology 34(27),1-18. 
Phelps, J., Stempel, L., \& Speck, G. (1985). The Children's handwriting scale: A new diagnastic tool. Journal of Educational Research,79(1), 46-50.

Power, B. M., \& Hubbard, R. S. (1996). Language development a reader for teachers. New Jersey: Prentice Hall Inc.

Ross, A. C.(2016). Wrist and hand. Pectoral girdle and upper limb (ed. Rolfe Birch). Gray's anatomy (41. Bask1), (ed. Susan Standring). London: Elsevier, 862-877.

Schneck, C. M. (1991). Comparison of pencil-grip patterns in first graders with good and poor writing skills. The American Journal of Occupational Therapy, 45(8), 701-706.

Schneck, C. M., \& Henderson, A. (1990). Descriptive analysis of the developmental progression of grip position for pencil and crayon control in nondysfunctional children. The American Journal of Occupational Therapy, 44(10), 893-900.

Summers, J., \& Catarro, F. (2003). Assessment of handwriting speed and factors influencing written output of universitiy students in examinations. Australian Occupational Therapy Journal, 50, 148-157.

Tashakkori, A., \& Teddlie, C. (Eds). (2003). Handbook of mixed methods in social and behavioral research. Thousand Oaks, CA: Sage.

Taylor, J. (2006). Developing handwriting skills. Stackhouse, J.(Eds.) A practitioner's handbook. Dislexia. Speech and language (2nd Edition), (229-252). London: Whurr Publishers

Taylor, J. S. (2010). Supervision and teaching of handwriting. U.K.: Lightning source.

Tok, R. ve Erdoğan, Ö. (2017) İlkokul 2. 3. ve 4. sınıf öğrencilerinin yazma becerilerinin incelenmesi. YYÜ Ĕgitim Fakültesi Dergisi, 14(1), 1003-1024.

Tseng, M. H. (1998). Development of pencil grip position in preschool children. Occupational Therapy Journal of Research,18, 207-224.

Tseng, M. H., \& Cermak S. A. (1993) The influence of ergonomic factors and perceptualmotor abilities on handwriting performance. American Journal of Occupational Therapy, 47(10), 919-926.

Uysal İ. İ. (2003) Nervus medianus'un klinik anatomisi ve varyasyonları. Genel Tip Dergisi, 13(2), 89-93.

Valantin P. (1981). Physiology of extension of the fingers. The hand. (Ed. Tubiana, R.) Philadelphia: Saunders, 389-98.

Vlachos, F., \& Bonoti, F. (2006). Explaining age and sex differences in children's handwriting: a neurobiological approach. European Journal of Developmental Psychology, 3(2), 113-123. 
Yıldırım, A. ve Şimşek, H. (2003). Sosyal bilimlerde nitel araştırma yöntemleri. Ankara: Seçkin Yayıncılık.

Yıldız, M., Açan, M., Berber, V., Bulut, S. ve Zalimhan, R. (2015). İlkokul öğrencilerinin yazma sürecindeki ergonomik tercihleri: tutma, el tercihi, oturuş ve kâğıt pozisyonu. International Journal Of Social Science, 40, 61-71.

Yıldız, M., Yıldırım, K. ve Ateş, S. (2009). Sınıf Öğretmenlerinin Sınıf Tahtasına Yazdıkları Yazıların Okunaklılık Bakımından Öğrencilere Model Olmadaki Uygunluğu. Uluslararası İnsan Bilimleri Dergisi, 6(2), 75-88.

Yılmaz, A. ve McMullan, M. B. (2010). Head start sinıflarında erken okuma-yazma müfredatını geliştirmeye yönelik bir çalışma. Ĕ̆itim ve Bilim, 35(158) 169-183.

Yücebaş, Ç. (2006). Grafik tasarımda görsel bütünlük oluşturmada tipografi ile görseller arasındaki ilişki ve sanat eğitimindeki yeri. (Yayınlanmamış doktora tezi). Dokuz Eylül Üniversitesi Eğitim Bilimleri Enstitüsü, İzmir.

Warwick, A. (2003). Nelson handwiritng: Resources and assessment. U.K.:Nelson Thornes. www.alfabesi.com/fenike-alfabesi [19.10.2019].

www.researchgate.net/figure/Movement-description-a-Shoulder-flexion-bElevation-inscapula-plane_fig3_318640138. [21.11.2019].

www.wfnk.com/2014/09/wrist-input-is-just-starting. [21.11.2019].

www.kenhub.com/en/library/anatomy/the-superficial-flexors-of-the-forearm. [15.11.2019]. www.kenhub.com/en/library/anatomy/radial-muscles-of-the-forearm. [15.11.2019]. www.anatomyinfo.com/hand-muscles. [15.11.2019]. www.zipfslaw.org/2018/08/12/motor-homunculus. [15.11.2019]. 
Başaran, M./ Pamukkale Üniversitesi Eğitim Fakültesi Dergisi, 52, 86-118, 2021

Ek 1: Çizgi Çizme Yönünün Çizgi Çizme Hızını Etkileme Durumunu Belirleme Ölçeği

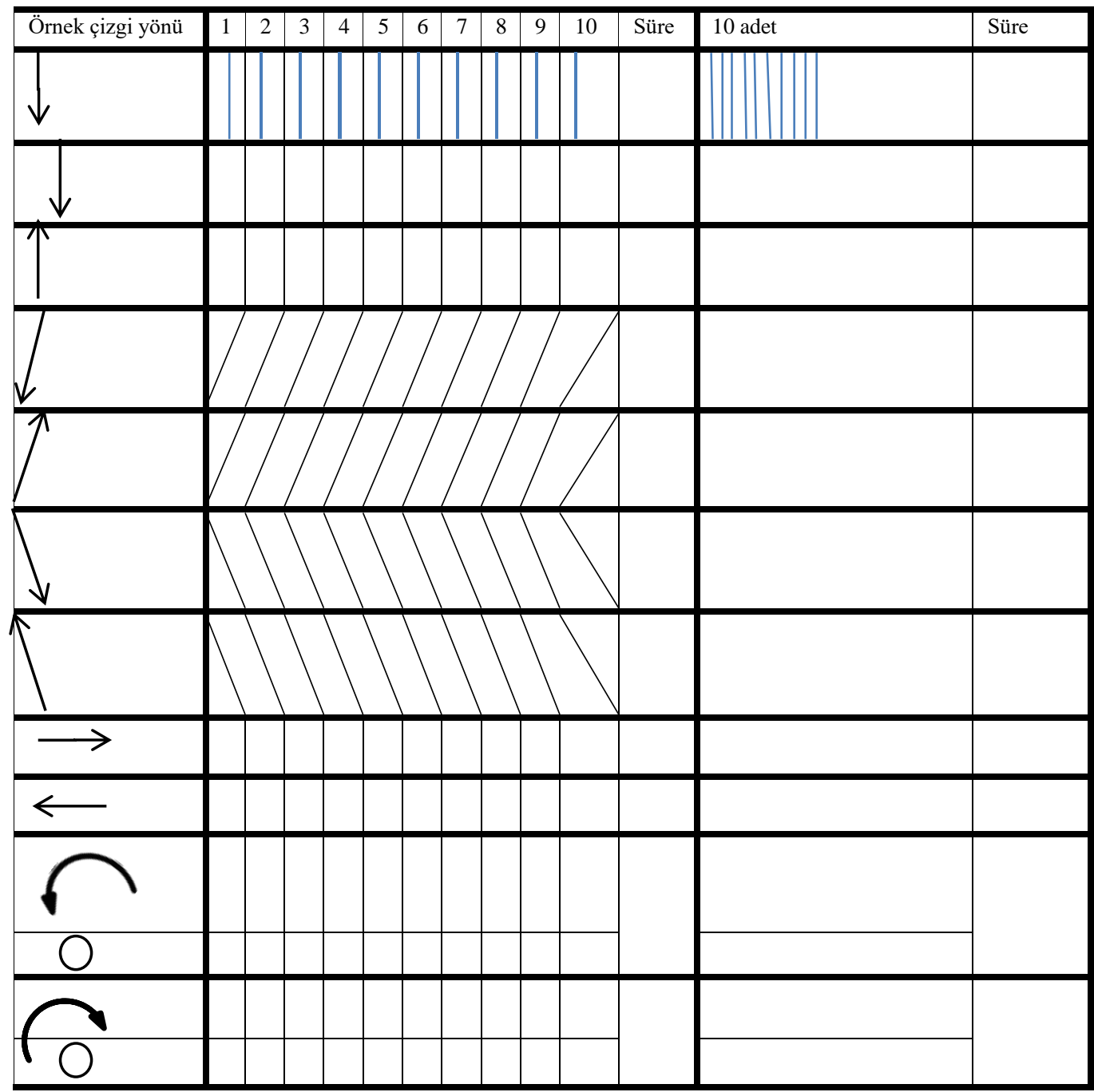




\section{Ek 2: Çizgi Niteliğini Belirleme Formu}

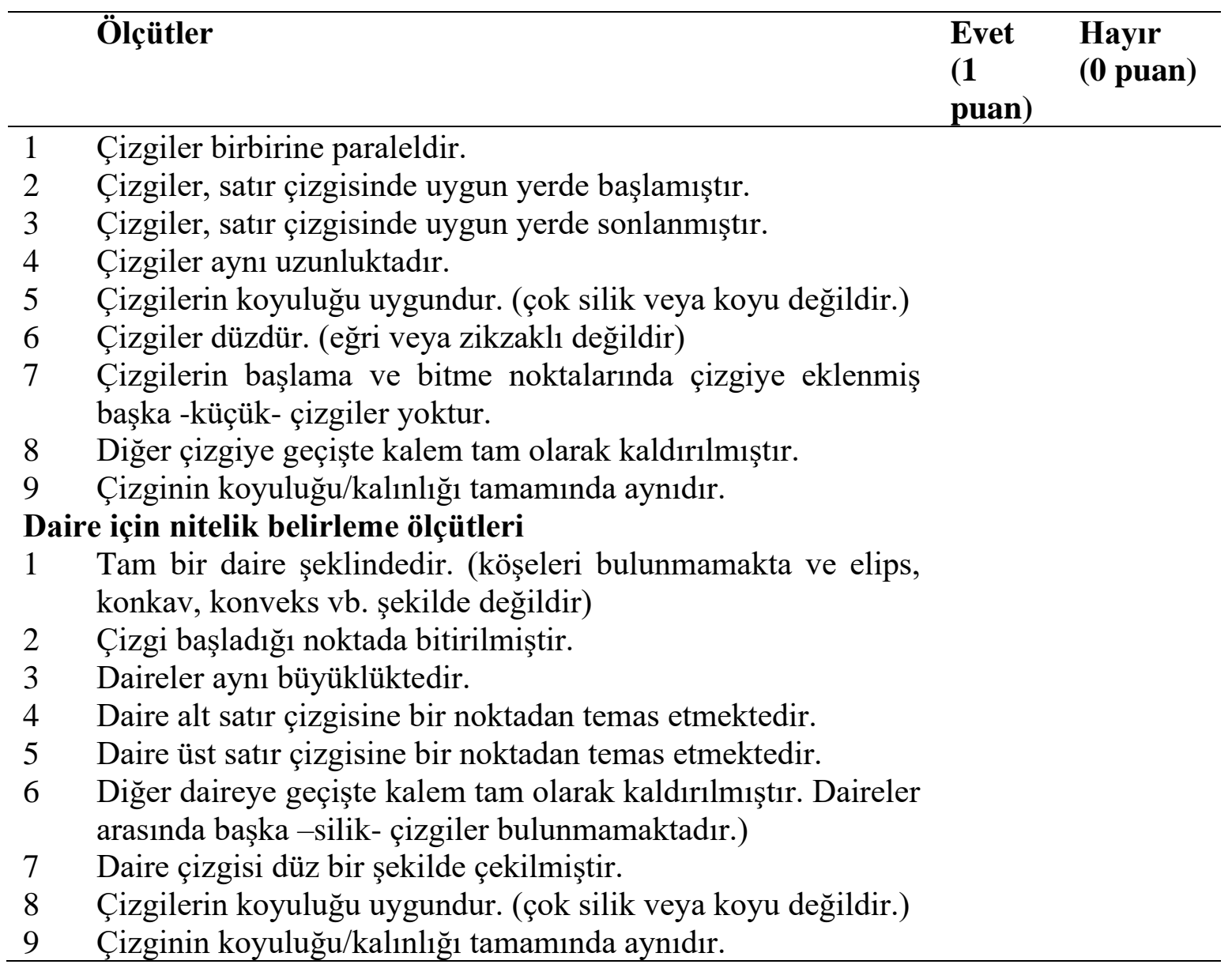


The Relationship between the Direction of Drawing the Letter Lines and the Drawing Speed and the Line Quality

\author{
Mustafa BAŞARAN*
}

- Received: $31.01 .2020 \bullet$ Accepted: 27.10.2020 • Online First: 27.10.2020

\begin{abstract}
The mixed-method was used in this study to determine the relationship between the direction of drawing the letter lines and the speed of drawing and the quality of the lines. The research study population consists of 1 st, 2nd, 3rd, and 4th-grade students who continue their education in public primary schools in Esenler and Zeytinburnu districts of Istanbul. A total of 164 students, 41 of which were 1st, 39 2nd, 40 3rd, and 44 th grade, selected using criterion sampling from purposeful sampling techniques, were determined as the study group. According to the research results, the line's drawing direction does not significantly affect the drawing time of the line in drawing a circle with vertical, oblique, and horizontal lines on the 1st, 2nd, 3rd, and 4th-grade levels. According to descriptive data, the vertical, right, and left slash lines at all grade levels are from top to bottom; horizontal lines were seen to be drawn faster from left to right. The circle's drawing direction has little effect on the drawing time of the circle; however, the circle is drawn faster than other lines. The lines' drawing direction is more effective on the quality of the lines than the line drawing speed. Students draw vertical and oblique letter lines from top to bottom; the line attributes increase when they draw the horizontal lines from left to right and the circle counterclockwise.
\end{abstract}

Keywords: Letter lines, writing speed, quality of letter lines

\title{
Cited:
}

Başaran, M. (2021). The relationship between the direction of drawing the letter lines and the drawing speed and the line quality. Pamukkale University Journal of Education, 52, 86118.doi:10.9779.pauefd.682929.

\footnotetext{
* Doç. Dr., Yıldız Teknik Üniversitesi, Eğitim Fakültesi, Temel Eğitim Böl. e-posta: mbasaran66@yahoo.com ORCID ID: 0000-0003-1684-5852
} 


\section{Introduction}

Language teaching aims to provide individuals with language skills that can be listed as reading, writing, listening, and speaking. Among these skills, it can be said that "writing" is the most important skill in creating civilization and passing it on to the next generation because writing makes the information produced permanent and transfers it to the next generation, and facilitates the sharing of information. When we look at the history of civilization, it is seen that all major transformations are related to writing: Oral culture in which knowledge is transferred through speech; a culture based on manuscripts starting with the discovery of writing; Typographic (printed) culture, beginning with the invention of the printing press in the mid-15th century, and digital culture, starting with the discovery of the telegraph (Donoughue, 2009). Writing skill is also extremely important for personal development and academic success. Students who do not have this skill may fail because they are insufficient in writing-based activities in the learning process or cannot fully convey their knowledge in written exams (Amudson, 2001; Baldini, 2000; Phelps, Stempel, \& Speck, 1985).

It is possible to define writing by producing and writing the necessary symbols and signs by the rules of the composition, language, and alphabet by the essay's rules, language, and alphabet (Akyol, 2012; Başaran \& Akyol, 2019). On the other hand, lettering can be defined as a tool that allows the words expressed with sounds to be recorded as signs, visible to the eye (Arseven, 1992).

Writing is the most difficult skill of all language skills. The reason for this is that writing requires skillfully using many cognitive, affective and psycho-motor behaviors that are used simultaneously while writing, all of which are acquired through practice, affect each other directly or indirectly but need to be considered and developed separately (Baştürk, 2004; Dodd \& Carr, 2003: 128; Güneyli, 2006; Power and Hubbard, 1996: 82).

Although writing is a skill with cognitive, affective and psycho-motor aspects, the literature on teaching writing (Ak \& Kesik, 2014; Ar1, 2010; Ayranc1, 2018; Cömert \& Aktaş, 2011; Çerçi \& Bardakçı, 2016; Erdoğan, 2017; Hamzadayı \& Çetinkaya, 2011; Tok \& Kurbaş \& Orhan, 2011), it is seen that the studies generally focus on the content of students' written products (cognitive behaviors related to writing). Still, the ergonomic factors affecting writing (psycho-motor behaviors related to writing) are not emphasized enough. Although the main goal in teaching writing is the content and function of the 
writing, the writing's aesthetic appearance is also important in the effective use of writing skills in daily life.

As in every job, ergonomic factors in writing also affect the quality of students' written products. Ergonomics is an engineering field that researches the necessary conditions for the comfortable and safe use of tools, equipment, or machines during a job (Güler, 2003; Iş11, 1991). Based on this definition, writing ergonomics can also be observed in writing activities in order to prevent negative situations such as pain, boredom, irritability, carelessness, inability to draw the letter lines correctly, slow blood circulation, fatigue, slow and illegible writing, students' direction of drawing the letter lines, holding a pencil, writing It is possible to define the correct behaviors related to arm positioning, positioning the free hand and sitting correctly while writing (Amundson \& Weil, 1996; Beaty \& Bratt, 2007; Havens, 2002; Taylor, 2006). Thus, students are less tired while writing; It can be said that teachers should focus not only on what students write but also on how they write (Taylor, 2010; Warwick, 2003) to make fewer mistakes and write faster and more clearly.

Writing ergonomics, which affects writing speed, quality of writing, and attitude towards writing (Akyol, 2005; Amundson, 1995; Beaty \& Bratt, 2007; Havens, 2002; Y1ld1z et al. 2015; Taylor, 2006), is mainly due to the structure, limitations, and functions of muscles and joints. While creating letters, even to draw a single line, many muscles, joints, and the nervous system that operate/control these muscles work in synchrony. These muscles can be briefly explained as follows (Barry \& Caffinere, 1981; Biant, 2016; Ellis, 1992; Gürcan \& Adiyaman, 2008; Kahraman, 2001; Lambert, 2016; Lubahn, 1996; Ross, 2016; Uysal, 2003; Valantin, 1981):

Since the shoulder muscles (deltoideus, subscapularis, supraspinatus, infraspinatus, teres major, and teres minor) are suitable for performing large motor movements, they are used the arm and hand in the proper position during writing. The movements made by the shoulder muscles are shown in Figure 1. The movements that the shoulder muscles make to the arm during writing are to separate the arm from the body and bring it forward and downward to the table at a suitable angle. 


\begin{tabular}{|l|l|l|l|l|}
\hline Flexion & Extension & Abduction & Adduction & Inter. and external \\
rotation
\end{tabular}

Figure 1. Movements made by the shoulder muscles to the arm.

(www.researchgate.net/figure/Movement-description-a-Shoulder-flexion-bElevation-inscapula-plane_fig3_318640138

Forearm muscles (m. Palmaris longus, m. Pronotor teres, m. Flexor carpi radialis, m. Flexor carpi ulnaris, m. Flexor digitorum, m. Flexor digitorum, profundus, m. Flexor pollicis longus, superficialis, m. Pronotor quadratus, m. brachioradialis, m. extensor carpi radialis longus, $\mathrm{m}$. extensor carpi radialis brevis, $\mathrm{m}$. extensor digitorum, m. extensor digiti minimi, m. extensor carpi ulnaris, m. anconeus, m. supine, m. abductor pollicis longus, minator extensor pollicis longus, m. extensor pollicis brevis, and $\mathrm{m}$. extensor indices) are used to hold the wrist correctly in writing and move the pencil from left to right in word writing. These muscles are located on the inside and outside of the forearm. These muscles should be used to keep the hand at an appropriate angle for writing rather than fine motor movements during writing and to prevent the hand-foot from rubbing on the paper. The muscles' movements in the forearm. 2 and the muscles used actively during writing are shown in Figure 3. and Figure 4.

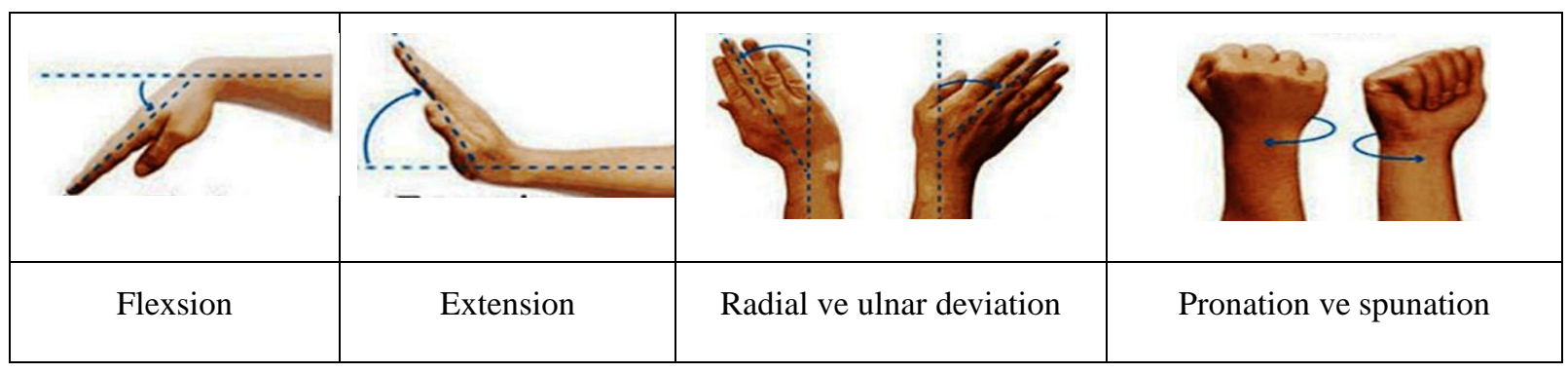

Figure 2. The movements of the muscles in the forearm. (www.wfnk.com/2014/09/wristinput-is-just-starting.) 


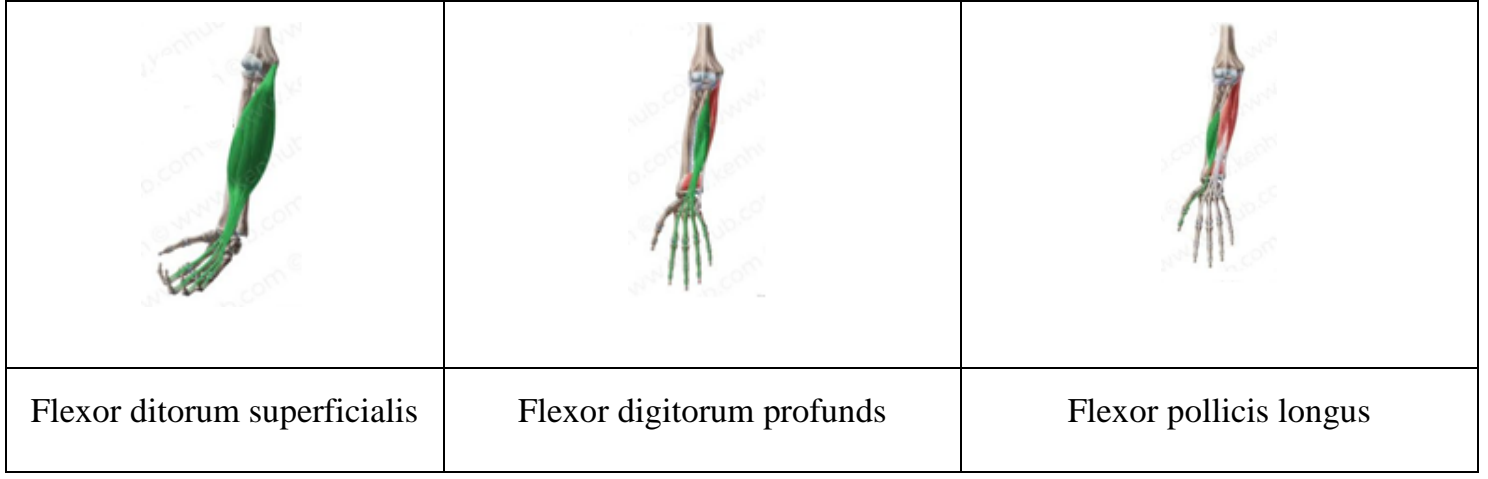

Figure 3.Muscles on the forearm that take an active part in writing. (www.kenhub.com/en/library/anatomy/the-superficial-flexors-of-the-forearm.)

\begin{tabular}{|c|c|c|c|}
\hline 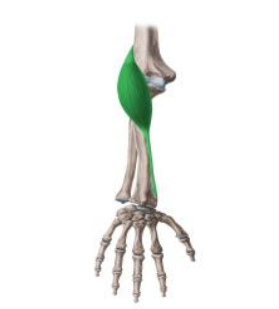 & का & N & 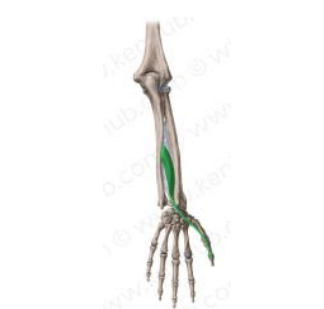 \\
\hline M. brachioradialis & M. extensor digitorum & M. abductor pollicis longus & M. ext. pollicis brevis \\
\hline
\end{tabular}

Figure 4. Muscles on the back surface of the forearm that are active in writing. (www.kenhub.com/en/library/anatomy/radial-muscles-of-the-forearm.)

The muscles examined so far are to perform gross motor movements and bring the hand to the appropriate position while writing. The muscles of the shoulder, arm (biceps, triceps), and forearm, including the back and back muscles, which bring and stabilize the body during writing, have an indirect effect on the writing's legibility and speed. However, writing requires making extremely small and controlled (fine motor) movements. Hand muscles that move the fingers are mostly used in writing.

There is no muscle on the outside of the hand. On the inside of the hand, there are specialized muscles to perform very sensitive movements. Four in the thenar area on the inner side of the hand (m. Abductor pollicis brevis, m. Opponens pollicis, m. Flexor pollicis brevis and adductor pollicis) four in the hypothenar (m. Palmaris brevis, m. Abductor digiti minimi, m. Flexor digiti minimi brevis and m. opponents digiti minimi) and four muscles in the middle region $(\mathrm{mm}$. lubricates, $\mathrm{mm}$. interosseous, $\mathrm{mm}$. interosseous dorsales and $\mathrm{mm}$. interosseous Palmares), there are a total of 12 muscles. The tenar region muscles are extremely important in terms of writing, as the thumb causes abduction, flexion, opposition, and adduction (see Figure 5.). The middle of the hand muscles are important for writing, 
especially since they make flexion, extension, and abduction to the index and middle finger (see Figures 6 and 7). The hypothenar region muscles should not be regarded as important in terms of writing since they are more effective in shaping the little finger and palm.

\begin{tabular}{|c|c|c|}
\hline abduksiyon extansiyon oppozisyon & 1 & (I) \\
\hline $\begin{array}{l}\text { Figure 5. Muscles made by } \\
\text { the thumb and used in writing } \\
\text { (www.anatomyinfo.com/hand } \\
\text {-muscles.) }\end{array}$ & $\begin{array}{l}\text { Figure 6. Tenar region } \\
\text { muscles } \\
\text { (www.anatomyinfo.com/han } \\
\text { d-muscles.) }\end{array}$ & $\begin{array}{l}\text { Figure } 7 . \text { Muscles in the } \\
\text { middle of the hand } \\
\text { (www.anatomyinfo.com/han } \\
\text { d-muscles.) }\end{array}$ \\
\hline
\end{tabular}

It is known that in the cortex (outer, the most developed) layer of the brain, certain areas are specialized for certain tasks and processes, and the larger the area of these regions, the more difficult, sensitive, or complex those tasks and processes are. The "motor cortex" located in the cortex layer of the brain is responsible for all body movements (see Figure 8.). This area is where the nervous stimulus sent to the muscles begins and is controlled. When looking at how much area is responsible for the movement of which organs in the motor cortex, it will be seen that most area is specialized for the hand, especially the thumb and face muscles (see Figure 9.). For this reason, it can be said that for behavior that requires extremely small and controlled movements such as writing, the thumb should be used predominantly.

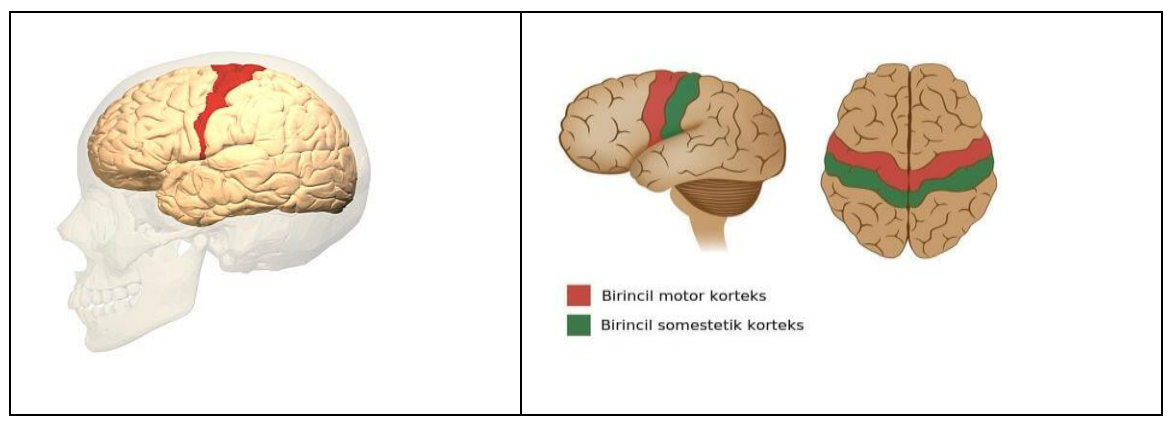

Figure 8. Motor kortex (www.musicalbrainwaves.weebly.com/motor-cortex.html.) 


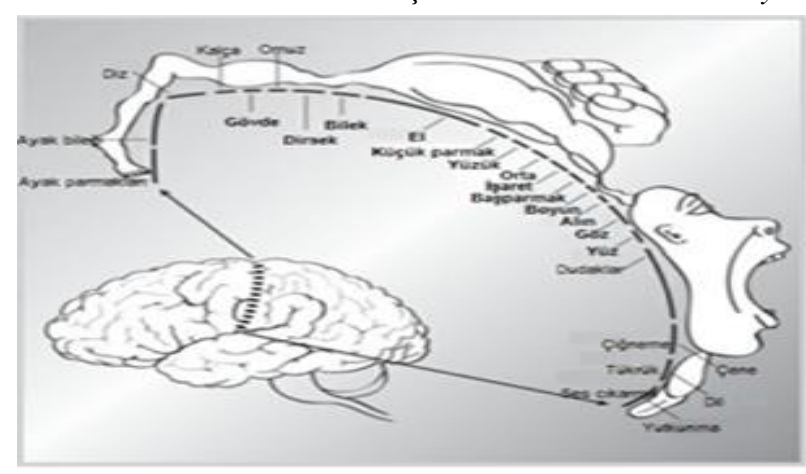

Figure 9. The size of the areas in the motor cortex is responsible for the muscles (www.zipfslaw.org/2018/08/12/motor-homunculus.)

As can be seen, even creating a single letter line is extremely complex, coordinated, and sequential; It is a difficult psycho-motor behavior that requires fine and gross motor movements.

They are writing speed and legibility of writing on neurological and posture, the pen's shape, etc. Besides physical factors, the shapes of the letters are also very effective. Letters are formed as a result of combining various lines depending on the alphabet and letter typography used. The rules under which the letters will be formed, the size or shape they will be used on two-dimensional surfaces, alone or in a word, and the combination depends on the letter typography (Yücebaş, 2006). When the typeface is used - typography changes, the lines forming the letters will also change structurally. For example, when using the cursive font typography in the Latin alphabet, the vertical line is not used; the places where horizontal lines are used are decreasing; The lines that are inclined to the right or left are drawn as curves, not lines.

In the first-grade classroom teachers in literacy education or other basic italic letters, Turkey is used depending on the choice (MEB, 2019: 10). These letters are formed by combining vertical, oblique, horizontal lines, half, and full circles. The Latin alphabet origin is based on the Phoenician alphabet (See Figure 1.), which is the first known alphabet. This alphabet's main feature is that it divides the spoken language into a series of sounds and is assigned extremely plain and few symbols for these sounds (Clair, 1999: 14). The Romans used this alphabet after the Phoenicians and has developed over time and has become used in all of Europe and finally in South and North America. With the invention of the printing press, many fonts/styles (typography) was used in this alphabet, but the letters' characteristic features remained the same in all these styles. 


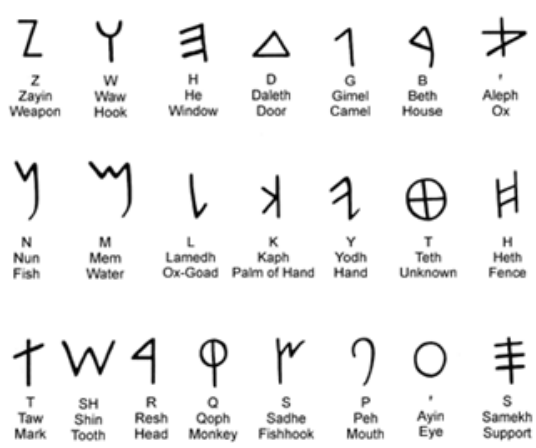

Figure 10. Phoenician Alphabet (www.alfabesi.com/fenike-alfabesi)

Latin alphabet is used since 1928 in Turkey. However, abece used in Turkey, the Latin alphabet is different from in other countries that use the alphabet's functioning. In this alphabet, 29 letters are symbolizing the 29 most commonly used sounds in standard Turkish; Each letter is written in the same way regardless of whether it is at the beginning-middle-end in the word, and the sound it symbolizes does not change at all regardless of the letter next to it. Considering these features ABEC uses the Latin alphabet; the alphabet used in Turkey is unlike any of the other countries; it seems to operate according to very simple rules without exception. However, although quite simple abece used in Turkey, especially in the last 20 years, which method in the first reading and writing instruction and continue discussions on the use of which font typography according to this method (Akyol 2012, Baştuğ \& Demirtas, 2016; Güneş, 2017; Red \& Ünal, 2016; Öz \& Çelik, 2015).

When the MEB Turkish course curricula were examined, it was found that information was given on the method and letter typography to be used in basal reading and writing; It is seen that writing ergonomics are emphasized in writing education (MEB, 2019: 10), but the drawing aspects of the letter lines are not emphasized (MEB, 2006; MEB, 2010; MEB, 2015; MEB, 2018; MEB, 2019). When we look at the studies on writing speed, legibility of writing, and writing ergonomics, it is seen that there is not enough emphasis on the direction of drawing the letter lines, drawing speed, and line quality. In these studies, writing speed and writing quality, pen shape (Alston, 1986; Halıc1, 2019), writing style (Bara, 2013), age, school, class, gender, hand used, paper posture, pencil grip, body posture, type of text, place of residence, pre-school education (Arslan \& Bağc1, 2017; Arslan \& Ilgın, 2010; Çevik, 2006; Doğan, 2007; Duran, 2011; Erdoğan, 2012; Höbek \& Taşkaya, 2018; Vlachos \& Bonoti, 2006; Y1ldız et al. 2015), classroom teacher (Başaran, 2006; Bayraktar, 2006) desk design (Kavak \& Bumin, 2009; Medwell \& Wray, 2007) visual perception (Memiş \& Harmankaya, 2012) the power of squeezing the pencil (Schneck, 1991; Schneck 
and Henderson, 1990; Summers and Catarro, 2003) and learning difficulties (Blöte and Hamstra, 1991; Fatemeh et al., 2008; Hamstra \& Blöte, 1993; Overlede et al. 2011). However, drawing the lines is also related to the typography of the letters and the ergonomics of writing. It has the potential to affect the speed of drawing and the quality of the line, thus the speed of writing and the legibility of the writing (Dennis \& Swinth, 2001; Koziatek \& Powell, 2003; Tseng, 1998; Brink \& Jacobs, 2011; Graham et al., 2006; Graham et al., 1998; Palmis et al., 2017; Tseng \& Cermak, 1993).

\section{Purpose of the research}

This study aimed to determine the effect of the direction of drawing the letter lines on the writing speed and the quality of the lines. For this purpose, the following sub-problems were sought in the study:

1- Is there a relationship between line drawing direction and drawing speed and line quality?

2- Is there a relationship between drawing letter lines with guiding lines and drawing speed and line quality?

3- Is there a relationship between gender and drawing speed and line quality?

4- Is there a relationship between grade level and drawing speed and line quality?

\section{Method}

A mixed method was used in this study. The mixed-method can be defined as the combined use of qualitative and quantitative paradigms, methods, or techniques in a study or consecutive studies. The main reason for using the mixed method in the research is that this method has "complementarity" due to its nature. Accordingly, using the mixed-method qualitative and quantitative data together reveals whether they support each other or these data are interpreted and interpreted together. In this way, research results can be further enriched (Butgel et al., 2016; Tashakkori \& Teddlie, 2003). Relational scanning is one of the quantitative research methods to determine the relationship between the direction of drawing the letter lines and the speed of drawing; Document analysis, one of the qualitative research methods, was used to determine the relationship between the quality of the lines.

The relational screening method is among the scanning patterns among quantitative research methods. In this design, the existence of a relationship between multiple situations, if there is a relationship, its degree is examined without the researcher (Creswell, 2011; 
Karasar, 2013). In document analysis, written, oral or visual materials containing information about the phenomenon or events aimed to be investigated are analyzed. It is possible to examine the data obtained through document analysis in-depth, and thus to reveal the relationships between the obtained data (Fitzgerald, 2012; Y1ldırım \& Şimşek, 2013).

\section{Working Group}

While determining the study group, criterion sampling, one of the purposeful sampling techniques, was used due to the research design. Purposeful sampling techniques allow for an in-depth examination of situations that are considered to have the rich and appropriate information in terms of the method and purpose of the research. Criterion sampling is selecting the working group from individuals, events, objects, or situations with certain qualities. In other words, it is the sampling of units that meet the criteria determined for the sampling (Büyüköztürk, 2010; Patton, 2002; Yıldırım \& Şimşek, 2013). In this study, 1st, 2nd, 3rd, and 4th-grade students who continue their education in public primary schools in Esenler and Zeytinburnu districts of Istanbul province constitute the study population. From this universe, a total of 164 students were reached, of which 41 were 1st, 39th 2, 40th 3rd, and 44th grade. While these students are included in the sample, students

1. Absence of special learning difficulties related to literacy such as dyslexia and dysgraphia

2. Have no physiological disability in writing

3. Families with immigrant status do not have children

4. To use basic vertical letters when writing

5. It has been examined that he has correct behaviors about holding a pencil, positioning the paper, and sitting in a row.

In this way, the research results are only affected by the direction of drawing the lines; it aims to control other variables that may affect the writing speed and line quality.

\section{Data Collection Tools}

Measurement tools developed by the researcher were used in the research. In the study, firstly, the line drawing direction developed to determine the effects of the direction of drawing the circle, perpendicular, left inclined, right inclined, and horizontal lines (Akyol, 2012; Binbaşığlu, 2004), which are mostly used in the writing of the basic vertical letters of 
students (Akyol, 2012; Binbaşığlu, 2004) Identification Scale was used (Appendix: 1). The semicircle is not included in the measurement tool because it is used very little, and its shape/position changes according to the characteristics of the letters. For the study, the direction in which these lines will be drawn is also shown in the measuring tool: Students use the vertical line from top to bottom and bottom to top; left slant and right slant line from top right to bottom left, bottom left to top right; top left to the bottom right and bottom right to top left; the horizontal line from left to right and right to left; They were asked to draw the circle clockwise and counterclockwise. The students were asked to draw ten lines from each line, considering that a single line they draw cannot show the speed of drawing the line and the quality of the lines and the data were obtained over ten lines. This scale was also modified to determine the effect of drawing lines with and without guide lines on line drawing speed and line quality. The validity of the scale was ensured by taking the opinions of five experts who have completed their doctorate in Turkish teaching.

In order to determine the quality of the lines, the Line Quality Determination Form (Appendix-2) developed by the researcher was used. This measurement tool has been arranged as an observation form in order to determine to what extent the line drawn by the student has the specified properties. The validity of the scale was ensured by taking the opinions of five field experts who completed their doctorate in the field of teaching Turkish. Nine criteria are specified for the lines. If the ten lines drawn by the students reflect the situation in a general criterion, the student is given a score of " 0 ", if not " 1 " from the relevant criterion. The highest score a student can get from this scale is 9 , and the lowest score is 0 . For this reason, the group of lines with a total score between 0 and 3 is low; Those between 4-6 points are considered medium, and those between 7-9 points are considered as good quality.

\section{Data Collection Process}

All stages of the research were carried out by the researcher. All applications during the data collection process were carried out in a classroom environment. One state school was determined in the Esenler and Zeytinburnu districts of Istanbul. The classroom teachers of the 1st, 2nd, 3rd, and 4th classes of these schools were interviewed, and the qualifications of the students to be included in the study were explained to these teachers. In the classes of volunteer teachers, the students suggested by the teachers were observed in activities requiring writing, and it was determined which students to work within that class. The "Scale for Determining the Affecting the Line Drawing Speed of Line Drawing Direction" 
was applied to the identified students. After the students drew ten lines as shown on the scale, it was recorded how long this process took, and then the student was asked to draw the next ten lines. The whole process has been recorded by video. In the second stage of the research, the quality of the lines was determined. For this, the "Line Quality Determination Observation Form" was used. The lines drawn by the students were scored separately by a field specialist who completed his doctorate in the field of Turkish teaching and two field experts who completed his master's degree in this field. For the students who gave different points by the experts, the lines were re-examined by three experts together, and the points of that student were given the points agreed by the experts.

\section{Data Analysis}

In this section, the findings of the research are presented and interpreted in tables.

Table 1. The Relationship Between the Direction of Drawing the Letter Lines and the Line Drawing Speed (sec.)

\begin{tabular}{|c|c|c|c|c|c|c|}
\hline Glass & $\begin{array}{l}\text { Line / line } \\
\text { direction }\end{array}$ & $\mathrm{N}$ & $X$ & SD & $\mathrm{t}$ & $\mathrm{p}$ \\
\hline 1 & VLDFTTB & 41 & 22,11 & 11,77 & 511 & ,611 \\
\hline \multirow[t]{9}{*}{$\mathrm{df}=80$} & VLDFBTT & 41 & 23,42 & 11,35 & & \\
\hline & RSDFTTB & 41 & 22,45 & 10,53 & ,339 & ,735 \\
\hline & OLDFBTR & 41 & 23,21 & 9,85 & & \\
\hline & LSDFTTB & 41 & 22,52 & 8,83 &, 150 &, 881 \\
\hline & OLDFATL & 41 & 22,83 & 9,71 & & \\
\hline & HLDFLTR & 41 & 21,21 & 9,48 & ,337 & ,737 \\
\hline & HLDFRTL & 41 & 21,92 & 9,63 & & \\
\hline & $\mathrm{CCC}$ & 41 & 17,40 & 6,13 & ,409 & ,684 \\
\hline & $\mathrm{CDC}$ & 41 & 17,97 & 6,49 & & \\
\hline 2 & VLDFTTB & 39 & 20,87 & 12,82 & 1,277 & ,205 \\
\hline \multirow[t]{6}{*}{$\mathrm{df}=76$} & VLDFBTT & 39 & 24,56 & 12,71 & & \\
\hline & RSDFTTB & 39 & 21,82 & 10,32 & ,808 &, 422 \\
\hline & OLDFBTR & 39 & 23,92 & 12,55 & & \\
\hline & LSDFTTB & 39 & 20,46 & 10,56 & ,903 &, 370 \\
\hline & OLDFATL & 39 & 22,58 & 10,25 & & \\
\hline & HLDFLTR & 39 & 20,30 & 9,27 & 1,105 & ,273 \\
\hline
\end{tabular}




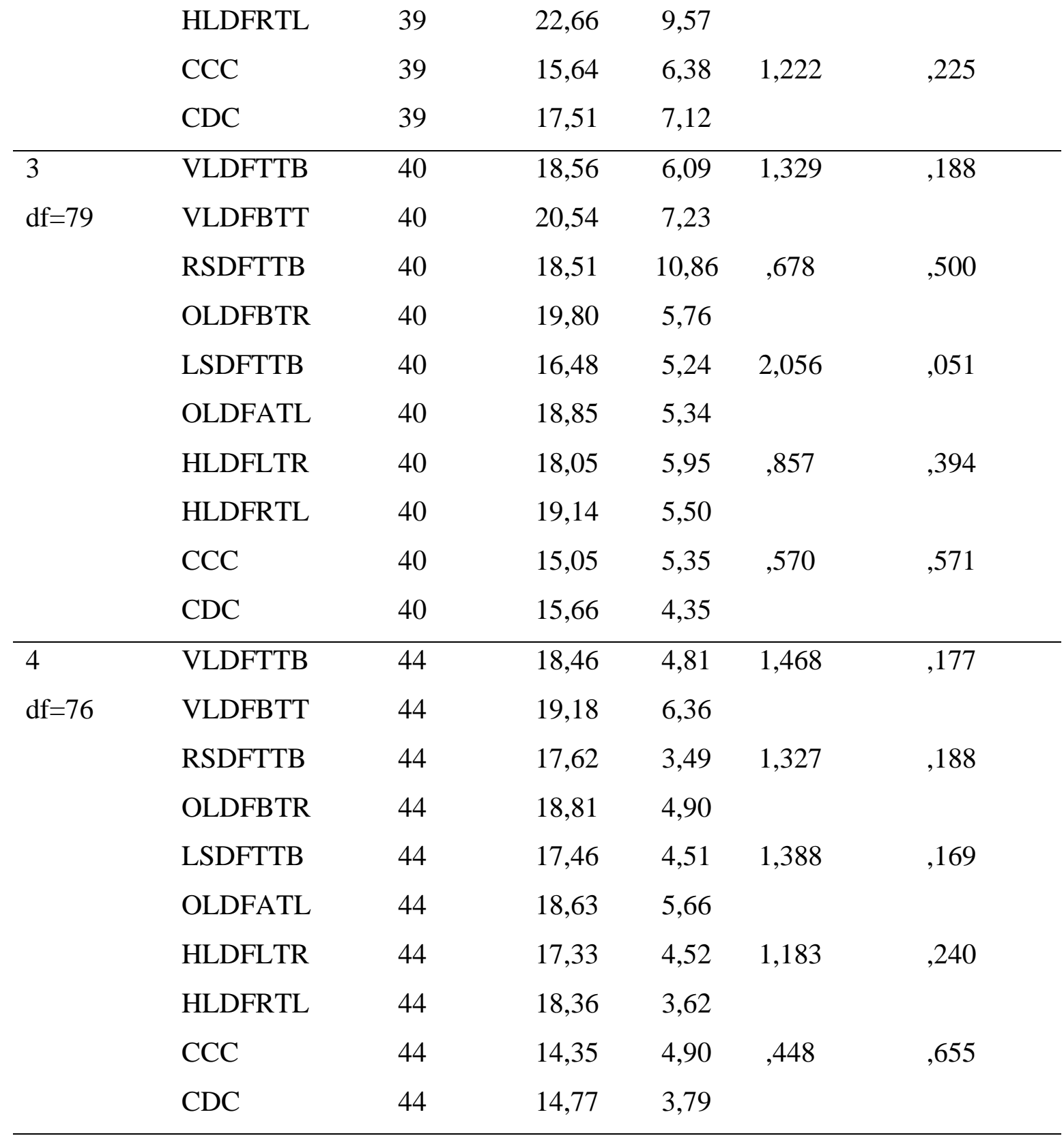

Note: VLDFTTB: a vertical line drawn from top to bottom; VLDFBTT: Vertical line is drawn from bottom to top; RSDFTTB: Right slash drawn from top to bottom; OLDFBTR: Oblique line drawn from bottom to right; LSDFTTB: Left slash drawn from top to bottom; OLDFATL: Oblique line drawn from above to the left; HLDFLTR: Horizontal line drawn from left to right; HLDFRTL: Horizontal line drawn from right to left; CCC: Counter-clockwise circle; CDC: Clockwise drawn circle

Table 1. shows ten vertical lines from top to bottom and bottom to top of primary school students attending 1st, 2nd, 3rd and 4th grades; the slash to the right from the topright corner to the left-bottom, from the left-bottom corner to the right-top; left slash from the upper left corner to lower right corner and lower right corner to upper left corner; Whether drawing the horizontal line from left to right and from right to left and the time of 
drawing the circle clockwise and counterclockwise made a significant difference. When Table 1 is examined, it is seen that the direction of drawing the line does not have a significant effect on the drawing time of the line in drawing a circle with vertical, oblique, horizontal lines at the 1, 2, 3, and 4-grade levels ( $p>.05$ ). However, when the descriptive data in the table are examined, the vertical, right, and left slash lines at all grade levels are seen from top to bottom; horizontal lines are drawn faster from left to right; It can be said that the circle is drawn faster than the other lines and the direction of drawing the line is the least effect on the speed compared to the other lines.

Table 2. Relationship between the Direction of Drawing the Letter Lines and the Quality of the Lines

\begin{tabular}{|c|c|c|c|c|c|c|}
\hline Glass & $\begin{array}{l}\text { Line / line } \\
\text { direction }\end{array}$ & $\mathrm{N}$ & $\mathrm{X}$ & SD & $\mathrm{t}$ & $\mathrm{p}$ \\
\hline 1 & VLDFTTB & 41 & 2,69 & ,51 & 3,164 & ,002 \\
\hline \multirow[t]{9}{*}{$\mathrm{df}=80$} & VLDFBTT & 41 & 2,20 & ,85 & & \\
\hline & RSDFTTB & 41 & 2,53 &, 74 & 1,995 & ,049 \\
\hline & OLDFBTR & 41 & 2,15 & ,86 & & \\
\hline & LSDFTTB & 41 & 2,52 &, 76 & 1,955 & ,058 \\
\hline & OLDFATL & 41 & 2,17 & ,84 & & \\
\hline & HLDFLTR & 41 & 2,38 & ,66 & ,385 &, 702 \\
\hline & HLDFRTL & 41 & 2,32 & ,65 & & \\
\hline & $\mathrm{CCC}$ & 41 & 1,95 & ,66 & 1,462 & , 148 \\
\hline & $\mathrm{CDC}$ & 41 & 1,75 &, 58 & & \\
\hline 2 & VLDFTTB & 39 & 2,46 & ,71 & 3,541 & ,001 \\
\hline \multirow[t]{9}{*}{$\mathrm{df}=76$} & VLDFBTT & 39 & 1,84 & ,81 & & \\
\hline & RSDFTTB & 39 & 2,25 & ,81 & 2,222 & ,029 \\
\hline & OLDFBTR & 39 & 1,84 & ,81 & & \\
\hline & LSDFTTB & 39 & 2,17 & ,72 & ,620 &, 537 \\
\hline & OLDFATL & 39 & 2,07 &, 73 & & \\
\hline & HLDFLTR & 39 & 2,30 & ,65 & 1,318 & ,191 \\
\hline & HLDFRTL & 39 & 2,10 &, 71 & & \\
\hline & $\mathrm{CCC}$ & 39 & 1,89 &, 75 & 2,061 & ,043 \\
\hline & $\mathrm{CDC}$ & 39 & 1,58 &, 54 & & \\
\hline 3 & VLDFTTB & 40 & 2,38 & ,74 & 1,538 & ,128 \\
\hline
\end{tabular}




\begin{tabular}{|c|c|c|c|c|c|c|}
\hline \multirow{10}{*}{$\begin{array}{l}100 \\
\mathrm{df}=78\end{array}$} & \multicolumn{5}{|c|}{ M. Başaran / Pamukkale University Journal of Education, 52, 86-118, 2021} & \multirow[b]{3}{*}{,271 } \\
\hline & VLDFBTT & 40 & 2,11 & ,80 & & \\
\hline & RSDFTTB & 40 & 2,46 & ,75 & \multirow[t]{2}{*}{1,109} & \\
\hline & OLDFBTR & 40 & 2,26 &, 85 & & \\
\hline & LSDFTTB & 40 & 2,41 & ,71 & \multirow[t]{2}{*}{,482 } & \multirow[t]{2}{*}{,631 } \\
\hline & OLDFATL & 40 & 2,33 & ,72 & & \\
\hline & HLDFLTR & 40 & 2,41 & ,63 & \multirow[t]{2}{*}{, 037} & \multirow[t]{2}{*}{,971 } \\
\hline & HLDFRTL & 40 & 2,40 & ,70 & & \\
\hline & $\mathrm{CCC}$ & 40 & 1,98 &, 82 & \multirow[t]{2}{*}{2,596} & \multirow[t]{2}{*}{,011 } \\
\hline & $\mathrm{CDC}$ & 40 & 1,83 &, 72 & & \\
\hline 4 & VLDFTTB & 44 & 1,95 & ,90 & ,363 & ,718 \\
\hline \multirow[t]{9}{*}{$\mathrm{df}=86$} & VLDFBTT & 44 & 1,88 &, 89 & & \\
\hline & RSDFTTB & 44 & 2,17 &, 86 & \multirow[t]{2}{*}{,959 } & \multirow[t]{2}{*}{,340 } \\
\hline & OLDFBTR & 44 & 2,00 & ,88 & & \\
\hline & LSDFTTB & 44 & 2,22 &, 76 & \multirow[t]{2}{*}{,776 } & \multirow[t]{2}{*}{,440 } \\
\hline & OLDFATL & 44 & 2,09 &, 83 & & \\
\hline & HLDFLTR & 44 & 2,22 &, 80 & \multirow[t]{2}{*}{,159 } & \multirow[t]{2}{*}{,874 } \\
\hline & HLDFRTL & 44 & 2,20 &, 81 & & \\
\hline & $\mathrm{CCC}$ & 44 & 2,00 & ,90 & \multirow[t]{2}{*}{2,391} & \multirow[t]{2}{*}{,019 } \\
\hline & $\mathrm{CDC}$ & 44 & 1,89 & ,69 & & \\
\hline
\end{tabular}

VLDFTTB: a vertical line drawn from top to bottom; VLDFBTT: Vertical line drawn from bottom to top; RSDFTTB: Right slash drawn from top to bottom; OLDFBTR: Oblique line drawn from bottom to right; LSDFTTB: Left slash drawn from top to bottom; OLDFATL: Oblique line drawn from above to the left; HLDFLTR: Horizontal line drawn from left to right; HLDFRTL: Horizontal line drawn from right to left; CCC: Counter-clockwise circle; CDC: Clockwise drawn circle

When Table 2 is examined, the direction of drawing the letter lines in 1st and 2nd grade is the vertical line, right slash, and circle; In the 3rd and 4th grades, it is seen that it makes a significant difference in the quality of the circle and does not cause a significant difference on the other letter lines ( $\mathrm{p}<.05)$. When these results are examined together with the relevant descriptive data, it can be said that drawing the vertical and right slash lines from top to bottom increases the quality of the line. Also 1-4. Drawing the circle counterclockwise at grade level increases the quality of the circle line. However, when the descriptive data in the table are examined, the vertical, right, and left slash lines at all grade levels are seen from top to bottom; horizontal lines from left to right; If the circle is drawn counterclockwise, it can be said that the lines are more qualified. In addition, according to 
the table, it is seen that the lines drawn for the circle at each grade level are the least qualified lines.

Table 3. Relationship between Gender Variable and Line Drawing Speed

\begin{tabular}{lcccccccc}
\hline \multicolumn{1}{c}{$\begin{array}{c}\text { Variables } \\
\text { df=162 }\end{array}$} & \multicolumn{7}{c}{ Girl } & \multicolumn{5}{c}{ Boy } & t & $\mathrm{p}$ \\
\cline { 2 - 6 } & $\mathrm{N}$ & $\mathrm{X}$ & $\mathrm{SD}$ & $\mathrm{N}$ & $\mathrm{X}$ & $\mathrm{SD}$ & & \\
\hline YADÇ & 88 & 15,94 & 8,04 & 76 & 21,88 & 12,08 & 3,379 &, 000 \\
AYDÇ & 88 & 18,71 & 5,28 & 76 & 19,53 & 6,16 &, 921 &, 358 \\
YASEÇ & 88 & 19,43 & 7,42 & 76 & 21,25 & 8,89 & 1,427 &, 156 \\
AYSEÇ & 88 & 18,80 & 5,26 & 76 & 19,57 & 5,94 &, 882 &, 379 \\
YASOEÇ & 88 & 17,86 & 7,52 & 76 & 20,39 & 9,01 & 1,960 &, 052 \\
AYSOEÇ & 88 & 17,93 & 4,56 & 76 & 19,13 & 6,00 & 1,451 &, 149 \\
SOSYÇ & 88 & 18,02 & 6,01 & 76 & 20,56 & 9,10 & 2,135 &, 034 \\
SASYÇ & 88 & 18,44 & 3,82 & 76 & 18,46 & 4,62 &, 026 &, 979 \\
CCC & 88 & 15,70 & 6,29 & 76 & 15,92 & 5,27 &, 237 &, 813 \\
CDC & 88 & 14,69 & 4,15 & 76 & 16,14 & 4,65 & 2,111 &, 036 \\
\hline
\end{tabular}

VLDFTTB: vertical line drawn from top to bottom; VLDFBTT: Vertical line drawn from bottom to top; RSDFTTB: Right slash drawn from top to bottom; OLDFBTR: Oblique line drawn from bottom to right; LSDFTTB: Left slash drawn from top to bottom; OLDFATL: Oblique line drawn from above to the left; HLDFLTR: Horizontal line drawn from left to right; HLDFRTL: Horizontal line drawn from right to left; CCC: Counter-clockwise circle; CDC: Clockwise drawn circle

Table 3 contains data on the effect of gender variable on the speed of drawing the lines. The gender variable significantly affects the drawing speed of the circle drawn in a clockwise direction with the vertical line from top to bottom, horizontal line from left to right $(\mathrm{p}<.05)$. When this result is examined together with the relevant descriptive data, it can be interpreted that the female students draw the vertical line faster from top to bottom, the horizontal line from left to right, and the circle clockwise. Besides, when all the descriptive data in the table are examined as a whole, it can be said that the female students draw all the letter lines faster.

Table 4. The Relationship Between the Gender Variable and the Quality of the Lines

\begin{tabular}{|c|c|c|c|c|c|c|c|c|}
\hline \multirow{2}{*}{$\begin{array}{l}\text { Variables } \\
\mathrm{df}=162\end{array}$} & \multicolumn{3}{|c|}{ Girl } & \multicolumn{3}{|c|}{ Boy } & \multirow[t]{2}{*}{$\mathrm{t}$} & \multirow[t]{2}{*}{$\mathrm{p}$} \\
\hline & $\mathrm{N}$ & $X$ & SD & $\mathrm{N}$ & $X$ & SD & & \\
\hline YADÇ & 88 & 2,51 & ,66 & 76 & 2,40 &, 73 & ,944 & ,346 \\
\hline AYDÇ & 88 & 2,26 &, 80 & 76 & 2,02 &, 81 & 1,847 & ,067 \\
\hline YASEÇ & 88 & 2,44 &, 80 & 76 & 2,38 &, 73 & ,507 & 613 \\
\hline
\end{tabular}


102

$\begin{array}{lllllllll}\text { AYSEÇ } & 88 & 2,13 & , 92 & 76 & 2,27 & , 77 & 1,040 & , 300 \\ \text { YASOEÇ } & 88 & 2,30 & , 71 & 76 & 2,42 & , 67 & 1,043 & , 298 \\ \text { AYSOEÇ } & 88 & 2,28 & , 74 & 76 & 2,31 & , 69 & , 281 & , 779 \\ \text { SOSYÇ } & 88 & 2,25 & , 69 & 76 & 2,50 & , 56 & 2,535 & , 012 \\ \text { SASYÇ } & 88 & 2,20 & , 77 & 76 & 2,34 & , 74 & 1,157 & , 249 \\ \text { CCC } & 88 & 1,96 & , 77 & 76 & 2,22 & , 74 & 2,264 & , 025 \\ \text { CDC } & 88 & 1,75 & , 63 & 76 & 1,77 & , 81 & , 197 & , 844\end{array}$

VLDFTTB: vertical line drawn from top to bottom; VLDFBTT: Vertical line drawn from bottom to top; RSDFTTB: Right slash drawn from top to bottom; OLDFBTR: Oblique line drawn from bottom to right; LSDFTTB: Left slash drawn from top to bottom; OLDFATL: Oblique line drawn from above to the left; HLDFLTR: Horizontal line drawn from left to right; HLDFRTL: Horizontal line drawn from right to left; CCC: Counter-clockwise circle; CDC: Clockwise drawn circle

Table 4 contains data regarding the effect of gender variable on the quality of lines. The gender variable significantly affects the quality of the circle drawn clockwise with the horizontal line from left to right $(\mathrm{p}<.05)$. When this result was examined together with the relevant descriptive data, it was seen that the left-to-right horizontal line drawn by the female students and the circle they drew in a clockwise direction was more qualified. They did not have a significant effect on the other letter lines.

Table 5. Relationship between Grid Lines and Line Drawing Speed

\begin{tabular}{lcccccccc}
\hline Variables & \multicolumn{7}{c}{ Has a guiding line } & \multicolumn{7}{c}{ No a guiding line } & \multirow{2}{*}{ t } & $\mathrm{p}$ \\
\cline { 2 - 6 } df:162 & $\mathrm{N}$ & $\mathrm{X}$ & $\mathrm{SD}$ & $\mathrm{N}$ & $\mathrm{X}$ & $\mathrm{SD}$ & & \\
\hline VLDFTTB & 164 & 19,15 & 9,66 & 164 & 16,18 & 6,55 & 3,038 &, 003 \\
VLDFBTT & 164 & 19,09 & 5,70 & 164 & 15,58 & 5,35 & 5,724 &, 000 \\
RSDFTTB & 164 & 20,27 & 8,16 & 164 & 17,83 & 9,69 & 2,322 &, 021 \\
OLDFBTR & 164 & 19,16 & 5,58 & 164 & 16,72 & 4,97 & 4,167 &, 000 \\
LSDFTTB & 164 & 19,03 & 8,31 & 164 & 15,89 & 6,00 & 3,919 &, 000 \\
OLDFATL & 164 & 18,48 & 5,29 & 164 & 15,36 & 4,44 & 5,761 &, 000 \\
HLDFLTR & 164 & 19,20 & 7,68 & 164 & 16,90 & 6,34 & 2,945 &, 003 \\
HLDFRTL & 164 & 18,45 & 4,20 & 164 & 16,00 & 5,07 & 4,739 &, 000 \\
CCC & 164 & 15,80 & 5,82 & 164 & 14,18 & 4,43 & 2,826 &, 005 \\
CDC & 164 & 15,36 & 4,43 & 164 & 13,00 & 2,54 & 5,882 &, 000 \\
\hline
\end{tabular}

VLDFTTB: vertical line drawn from top to bottom; VLDFBTT: Vertical line drawn from bottom to top; RSDFTTB: Right slash drawn from top to bottom; OLDFBTR: Oblique line drawn from bottom to right; LSDFTTB: Left slash drawn from top to bottom; OLDFATL: Oblique line drawn from above to the left; HLDFLTR: Horizontal line drawn from left to right; HLDFRTL: Horizontal line drawn from right to left; CCC: Counter-clockwise circle; CDC: Clockwise drawn circle 
Table 5 shows the effect of the guide lines on the line on the line drawing speed. According to the table, no matter which direction the guide lines are drawn, they have a significant effect on the speed of drawing vertical, oblique, and horizontal lines and drawing circles $(\mathrm{p}<.05)$. When this result is analyzed together with the descriptive data, it is seen that the guide lines decrease the speed of drawing the letter lines, regardless of the drawing direction. However, while reading this finding, it should be kept in mind that the values in seconds in the table are the time spent drawing ten lines in total. In other words, the difference is not due to the time spent drawing the lines; It is the time taken to raise the pen after drawing a line and put it in the proper place on the paper to draw the other line.

Table 6. Relationship between Grid Lines and Line Quality

\begin{tabular}{lcccccccc}
\hline Variable & \multicolumn{7}{c}{ Has a guiding line } & \multicolumn{7}{c}{ No a guiding line } & & & \\
\cline { 2 - 5 } \multicolumn{1}{c}{$\mathrm{N}$} & $\mathrm{N}$ & $\mathrm{X}$ & $\mathrm{SD}$ & $\mathrm{N}$ & $\mathrm{X}$ & $\mathrm{SD}$ & $\mathrm{t}$ & $\mathrm{p}$ \\
$\mathrm{df:} 162$ & & & & & & & & \\
\hline VLDFTTB & 164 & 2,45 &, 70 & 164 & 2,22 &, 72 & 2,928 &, 004 \\
VLDFBTT & 164 & 2,25 &, 81 & 164 & 2,03 &, 83 & 1,988 &, 041 \\
RSDFTTB & 164 & 2,41 &, 76 & 164 & 2,00 &, 77 & 4,811 &, 000 \\
OLDFBTR & 164 & 2,20 &, 85 & 164 & 1,89 &, 84 & 3,307 &, 001 \\
LSDFTTB & 164 & 2,35 &, 69 & 164 & 2,03 &, 72 & 4,171 &, 000 \\
OLDFATL & 164 & 2,29 &, 71 & 164 & 2,03 &, 77 & 3,241 &, 001 \\
HLDFLTR & 164 & 2,38 &, 64 & 164 & 1,99 &, 77 & 4,955 &, 000 \\
HLDFRTL & 164 & 2,26 &, 76 & 164 & 1,87 &, 78 & 4,646 &, 000 \\
CCC & 164 & 2,09 &, 77 & 164 & 1,81 &, 70 & 3,361 &, 001 \\
CDC & 164 & 1,76 &, 73 & 164 & 1,75 &, 83 & 1,403 &, 173 \\
\hline
\end{tabular}

VLDFTTB: vertical line drawn from top to bottom; VLDFBTT: Vertical line drawn from bottom to top; RSDFTTB: Right slash drawn from top to bottom; OLDFBTR: Oblique line drawn from bottom to right; LSDFTTB: Left slash drawn from top to bottom; OLDFATL: Oblique line drawn from above to the left; HLDFLTR: Horizontal line drawn from left to right; HLDFRTL: Horizontal line drawn from right to left; CCC: Counter-clockwise circle; CDC: Clockwise drawn circle

Table 6 shows the effect of the guide lines on the line on the quality of the lines. According to the table, no matter in which direction the guide lines are drawn, vertical, oblique, and horizontal lines and counterclockwise significantly affect the quality of the circle $(\mathrm{p}<.05)$. However, it has no significant effect on the circle drawn in a clockwise direction $(p>.05)$. When this result is examined together with the relevant descriptive data, it can be interpreted that the guide lines increase the quality of the letter lines regardless of the drawing direction except the circle drawn in clockwise direction. 
Table 7. Relationship between Grade Level and Line Drawing Speed and Line Quality

\begin{tabular}{lcccccccccc}
\hline Glass & VLD. & VBTT & RSD. & OLD. & LSD. & OLAL. & HLLR & HLRL. & CCC & CDC \\
\hline Speed &,$- 219^{* *}$ &,$- 279^{* *}$ &,- 099 &,$- 181^{*}$ &,$- 333^{* *}$ &,$- 178^{*}$ &,$- 179^{*}$ &,$- 200^{*}$ &,$- 309^{* *}$ &, 079 \\
Quality &, 001 & \multirow{2}{*}{, 035} &, 108 &, 011 &, 153 &, 003 &, 100 &, 054 &, 142 &, 008 \\
\hline
\end{tabular}

$* \mathrm{P}<.05, * * \mathrm{P}<.01$

Table 7 shows the relationship between grade level and line drawing speed and line quality. According to the table, except for drawing the vertical line from top to bottom and circle clockwise, there is a significant negative relationship between the time spent drawing all the lines and the grade level $(\mathrm{p}<.05)$. This result can be interpreted that the higher the grade level, the faster the students draw the letter lines, except for drawing a circle in a clockwise direction and slashing from top to bottom. There was no significant relationship between grade level and the quality of the lines $(p>.05)$.

Table 8. Relationship between Line Drawing Speed and Line Quality

\begin{tabular}{|c|c|c|c|c|c|c|c|c|c|c|}
\hline Pseed/qualit & & VBT & & & & & & & & \\
\hline $\mathrm{y}$ & VLD. & $\mathrm{T}$ & RSD. & OLD. & LSD. & OLAL. & HLLR & HLRL. & $\mathrm{CCC}$ & $\mathrm{CDC}$ \\
\hline VLDFTTB &, $283^{* *}$ & & & & & & & & & \\
\hline VLDFBTT & &, 054 & & & & & & & & \\
\hline RSDFTTB & & &, 053 & & & & & & & \\
\hline OLDFBTR & & & & ,080 & & & & & & \\
\hline LSDFTTB & & & & & ,038 & & & & & \\
\hline OLDFATL & & & & & &, 052 & & & & \\
\hline HLDFLTR & & & & & & & ,036 & & & \\
\hline HLDFRTL & & & & & & & &, 034 & & \\
\hline $\mathrm{CCC}$ & & & & & & & & & ,192* & \\
\hline $\mathrm{CDC}$ & & & & & & & & & & ,095 \\
\hline
\end{tabular}

Table 8 shows the data regarding the relationship between the lines' quality and the speed of drawing the lines. According to the table, there is a weak positive relationship between the vertical line drawn from top to bottom and the quality of the circle drawn in the anticlockwise direction, and the time spent drawing these lines ( $\mathrm{p}<.05)$. This finding can be interpreted as the more time taken to draw the vertical line drawn from top to bottom and the circle drawn counterclockwise (the slower you draw these lines), the more the lines' quality 
will increase. When the table is examined, it is seen that all correlation coefficients are positive though not significant. In other words, it can be said that attention should be paid to increasing the quality of the line and the speed of drawing.

\section{Discussion and Conclusion}

The first sub-problem of the study was, "Is there a relationship between the direction of line drawing and the drawing speed and line quality?" expressed in the form. According to the findings related to this sub-problem, there is no significant relationship between drawing direction of the line and drawing time of line in drawing circles with vertical, oblique, horizontal lines at 1st, 2nd, 3rd and 4th-grade levels. However, according to descriptive data, vertical, right and left slash lines at all grade levels are from top to bottom; horizontal lines are drawn faster from left to right. The circle is drawn faster than other lines. Also, the relationship between the drawing direction of the circle and the drawing speed is lower than the other lines.

According to the research findings, drawing speed is more effective on line quality than a line drawing direction. In other words, when students draw the lines more slowly, the quality of the lines increases. In addition, when students draw the vertical and oblique lines from top to bottom, the horizontal line from left to right, and the circle counterclockwise, the lines become more qualified. At the 1-4 grade level, the circle is lower than the other lines. In other words, the fastest circle is drawn at all grade levels, but the shape with the lowest quality is still the circle. These findings show that students use vertical and oblique letter lines from top to bottom while writing with basic vertical letters; the horizontal lines from left to right and the circle counterclockwise can be interpreted as boots that can increase the writing speed and quality.

It can be said that the working principles of the hand muscles, which are described in the conceptual framework and used actively during writing, are effective in the emergence of these results. When we think that the muscles that bend the thumb, index, and middle finger inward are both more sensitive and stronger than the muscles that open out, drawing the letter lines from top to bottom is an expected result to increase both the quality of the line and the speed of drawing.

Based on the findings obtained from the research and the information given about the muscular and nervous system related to writing so far, it can be said that the following principles should be considered in the process of teaching letter lines: 
- A student who bends his hand inward (crescent), bends his hand outward (showing the outside of the eraser side of the pencil), or holds the pencil with his side rather than with the tip of his thumb actively / dominantly uses the forearm muscles; It can be said that he tried to write with gross motor movements and that he was tiring these muscles more than necessary. However, these muscles are suitable for large motor skills and should be used sparingly to hold the hand properly.

- Although the muscles in the waist, back, shoulder, arm, and forearm are not actively used in writing, they have an indirect effect on writing speed and legibility, as these muscles are used to keep the hand and body in the proper position.

- Creating letter lines depends mostly on the muscles that move the thumb, then the index and middle finger. Many large and small muscles move the thumb compared to other fingers; Besides, there are only muscles in hand and forearm that move this finger very precisely; there is a large area responsible for this finger's movement in the motor cortex. Therefore, as with most manual work, the thumb should be used predominantly in writing.

- When the anatomy of the head, index, and middle finger is examined separately, it is seen that the muscles that bend these fingers towards the palm are much stronger than the muscles that open outwards, thus making the inward movements of these fingers stronger, easier and more precise.

- When the results obtained from the research are discussed through the relevant literature, drawing the lines from top to bottom, right to left, and the circle counterclockwise is more appropriate for hand anatomy; it can be said that it positively affects the speed and quality of the drawing. Based on these results, in preparation for writing activities in kindergarten and in line and letter studies in primary school first grades, teachers

- Students' vertical and curved lines from top to bottom; Paying attention to draw the horizontal lines from left to the right and the circle in the anticlockwise direction,

- Teaching students other behaviors that affect the ergonomics of writing, such as correct sitting, positioning the paper, and positioning the free hand,

- Teaching the correct handling of the pen, 
- The main function of the thumb when writing is to move the pencil; Explaining that the middle finger is to carry the weight of the pen and the index finger is to fix the pencil,

- In order to increase the quality of letter lines, it can be said that students should pay attention to the writing speed and that students with low quality of letter lines should want to write more slowly.

The second sub-problem of the study was, "Is there a relationship between guideline lines and drawing speed and line quality?" expressed in the form. In other words, in this study, the effect of lifting the pen tip and moving it to the appropriate place, which is another factor that takes time in writing letters, on writing speed and line quality was also examined. As a result of this application, it has been observed that drawing a line within the area determined by guideline lines, regardless of the drawing direction, reduces the drawing speed. In fact, the speed of drawing a single line into the designated area is the same starting from the specified point and starting from the desired place. The source of the difference observed here is that the time taken to lift the tip of the pen and put it in the appropriate point has a significant effect on the writing speed. These findings coincide with the results of the studies (Alston \& Taylor, 1987; Amudson, 2001; Başaran \& Karatay, 2005; Erdoğan, 2012; Güneş, 2017) which stated that lifting the pen tip and putting it at the appropriate point in the writing of basic vertical letters affects the writing speed. This finding may also be why drawing horizontal lines from left to right is faster than drawing from right to left. Because when the horizontal line is drawn in the direction of writing (from left to right), the pen's tip is lifted and taken to a very close point. When the horizontal line is drawn against the direction of writing (from right to left), the writing speed decreases as the pen's tip will be moved to a relatively far point.

In the research, it was concluded that drawing on the area separated by guideline lines increases the quality of the line, although it decreases the speed of drawing the line. Again, according to this study's results, the observed relationship between line drawing speed and line quality is quite low. From this point of view, the main factor that increases the quality of the lines drawn with guiding lines is not the slower drawing of the lines to the specified areas; it may be that students reference the guide lines while drawing. Based on this finding, it can be said that the practice of guide line (see Figure 10.) used in writing notebooks of primary school first-graders is appropriate, and teachers should warn students to refer to these lines while writing. 
Figure 11. Grid-lined notebook

The third sub-problem for which an answer was sought in the study is "Is there a relationship between gender and drawing speed and line quality?" and bulgur related to this problem is as follows: Female students draw all lines faster than male students. However, there is no significant difference between the characteristics of the lines of male and female students. These results can be interpreted as female students can write faster than male students, but gender has no effect on the text's readability and aesthetics. This finding is consistent with the findings of studies (Coşkun \& Coşkun, 2012; Cohen, 1997; Duran \& Akyol, 2010; Höbek \& Taşkaya, 2018) that investigated the effect of gender on the fluency or legibility of writing and reached the conclusion that female students wrote faster than male students. Female students can draw faster than male students because they have more advanced fine motor skills than male students. Besides, the fact that writing requires focusing and staying still for a long time and that male students, who are more active than female students, push more during writing may also be effective in these results (Erden \& Akman, 1998). Another reason for this result is selecting materials (romantic, emotional, lecturing, etc.) that will attract female students' attention (Güneş, 2016).

Based on these findings, it can be suggested that male students should not forget that writing problems may arise from developmental characteristics, while preschool and classroom teachers are conducting writing activities. They should also do practices that will allow students to rest or drain their energy at short intervals.

The fourth sub-problem of the study is, "Is there a relationship between grade level and drawing speed and line quality?" expressed in the form. According to the results, it can be said that the higher the grade level, the faster the letter lines are drawn regardless of the direction. This finding is consistent with the relevant literature (Arslan \& Bağc1, 2017; Arslan \& Ilgın, 2010; Çevik, 2006; Doğan, 2007; Duran, 2011; Vlachos \& Bonoti, 2006), which states that as the grade level increases, the writing speed will also increase. Looking at the relationship between the class level and the quality of the lines, it was seen that there was no significant relationship between these two variables. This finding shows that the quality of students' lines will be the same in later grades as in the first grades. 
Based on these findings, the first grade in writing education is more important than other grades; It can be said that many skills that are very important for writing, such as holding the pencil, sitting correctly, writing the letters correctly, drawing the letter lines correctly, and writing fast, beautiful and legible, which are also used in later grades, should be acquired in the first grade. Because these skills cannot be acquired in the first year, or if the student learns wrong behaviors related to the ergonomics of writing, it is much more difficult to correct these behaviors or to teach the correct behaviors in later classes (Başaran, 2006; Beaty \& Çetin, 2014; Bratt, 2007; Graham et al., 2008; Erden. and Altun, 2014; Y1ldız et al., 2009; Y1lmaz \& McMullan, 2010).

Ethical Approval: Since the data of this study were collected in 2019, the approval of the ethics committee was not obtained.

Conflict Interest: The author declare that he has no conflict of interest

Authors Contributions: Contribution to the preparation and revision of the article was made by the relevant author. 


\section{References}

Ak, B. D., \& Kesik, F. S. (2014). Yabancı dil olarak Türkçe öğrenen Balkanlı öğrencilerin yazılı anlatımda yaptıkları hatalar üzerine tespitler. Uluslararası Dil ve Edebiyat Ĕ̈itimi Dergisi, 10, 100-119.

Akyol, H. (2012). Türkçe ilk okuma yazma ögretimi (5 th. ed.). Ankara: Pegem A Yayınc1lık.

Alston, J., \& Taylor, J. (1987), Handwriting: Theory, research and practice. New York: Nichols Publishing.

Alston, J. (1986). The effects of pencil barrel shape and pupil barrel preference on hold or grip in 8-year-old pupils. British Journal of Occupational Therapy, 49(2), 42-44.

Amudson S. J. (2001). Prewriting and handwriting skills, occupational therapy for children. St. Louis, Missouri: Mosby.

Amundson, S. J. (1995). Eveluation children's handwriting. USA: O.T. Kids.

Arı, G. (2010). Altıncı ve yedinci sınıf öğrencilerinin yazdığı hikâye edici metinlerin değerlendirilmesi. $T \ddot{B} B A R, 15(27)$, 43-75.

Arseven, C. (1992). Yazı. Sanat Ansiklopedisi V. İstanbul: Milli Eğitim Basımevi.

Arslan, D., \& Bağcı, H. (2017). İlköğretim öğrencilerinin (2.-7. sınıf ) yazı hızı: kesit çalışması. Uluslararası Sosyal Araştırmalar Dergisi, 10(50), 451-461.

Arslan, D., \& Ilgın, H. (2010). Öğretmen ve öğrencilerin bitişik eğik yazı ile ilgili görüşleri. İnönü Üniversitesi Ĕ̌gitim Fakültesi Dergisi, 1( 2), 69-92.

Ayrancı, B. (2018). Eğitim fakültesi öğrencilerinin yazılı anlatım dersi uygulamalarında alanlarına özgü etkinlik oluşturma çalışmaları. Zeıtschrıft Für Dıe Welt Der Türken, 10(1), 143-157.

Baldini, M. (2000). Illetişim tarihi. İstanbul: Avcıol Basım Yayın.

Bara, F., \& Morin, M. F. (2013). Does the handwriting style learned in first grade determine the style used in the fourth and fifth grades and influence handwriting speed and quality? A comparison between french and quebec children. Psychology in the Schools, 50(6), 601-617.

Barry P. S., \& Caffinere J. Y. (1981). Physiology of flexion of the fingers. The Hand, 377388. (Ed. Tubiana R) Philadelphia: Saunders.

Başaran, M. (2006). “İlkokuma yazma öğretimi sürecinde öğrencilerin yaptıkları yazım yanlışları. Ulusal Sınıf Öğretmenliği Kongresi Gazi Üniversitesi, Bildiri Kitabı 1.Cilt, Ankara: Kök Yayıncılık. 
Başaran, M., \& Akyol, H. (2019). Dördüncü sınıf öğrencilerinin kalem tutuşlarının ergonomik unsurlar açısından incelenmesi. Okuma Yazma Eğitimi Araştırmaları, $7(1), 1-14$.

Başaran, M., \& Karatay, H. (2005). Eğik el yazısı öğretimi. Millî Eğitim Dergisi, 33(168), 27-34.

Başaran, M. (2006). İlkokuma-Yazma öğretimi sürecinde öğrencilerin yaptıkları yazım yanlışlıkları. Ulusal Sınıf Öğretmenliği Kongresi. (14-16 Nisan 2006). Ankara: Gazi Üniversitesi.

Bayraktar, Ö. (2006). İlköğretim birinci sınıf öğrencilerinin bitişik ĕgik yazıda yaptıkları hatalar. Unpublished doctoral dissertation, Gazi Üniversitesi Eğitim Bilimleri Enstitüsü, Ankara.

Baştuğ, M., \& Demirtaş, G. (2016). Her ses/harf için özel uygulamalı ilkokuma ve yazma ögretim el kitabı. Ankara: Pegem Akademi Yayınları.

Blöte, W. A., \& Hamstra B. L. (1991). A longitudinal study on structure of handwriting. Perceptual Motor Skills, 72(1), 983-994.

Baştürk, M. (2004). Dil edinim kuramları ve Türkçenin ana dili olarak edinimi. Ankara: PegemA Yayınc1lık.

Beaty, J. J., \& Bratt, L. (2007). Early literacy in preschool and kindergarten a multicultural perspective (2th ed.). New Jersey: Pearson Education Inc.

Biant, L. C. (2016). Elbow and forearm. Section 6: Pectoral girdle and upper limb (ed. Rolfe Birch), Gray's Anatomy (41th. ed.), (eds. Susan Standring), (pp. 837-862). London: Elsevier,

Binbaşığlu, C. (2004). Illkokuma ve yazma öğretimi, Ankara: Nobel Yayın Dağıtım.

Brink, A. O., \& Jacobs, A. B. (2011). Kinesthetic sensitivity and related measures of hand sensitivity in children with nonproficient handwriting. Pediatric Physical Therapy, 23(1), 88-94.

Butgel, T. S., Gözü, Ö., \& Özen, G. (2016). Nitel ve nicel araştırma yöntemlerinin bir arada kullanılması "karma araştırma yöntemi” Anadolu Üniversitesi Iletişim Bilimleri Fakültesi Uluslararası Hakemli Dergisi. 24(2), 106-112.

Clair, K. (1999). A typographic workbook. Canada: John Wiley \& Sons, Inc.

Cohen, M. R. (1997). Individual and sex differences in speed of handwriting among high school students. Perceptual and Motor Skills, 84(1), 1428-1430.

Coşkun, E., \& Coşkun, H. (2012). İlköğretim öğrencileri ile sınıf ve Türkçe öğretmenlerinin bitişik eğik yazı başarı düzeylerinin değerlendirilmesi. GUJGEF, 32(3), 761-776. 
Cömert, Ö., \& Aktaş, M. (2011). Matematik eğitiminde kullanılan simetrinin uygulandığı bir şeklin Türkçe ve ilköğretim matematik öğretmenliği 1. sınıf öğrencilerinin yazma becerilerine etkisi. Zeitschrift Für Die Welt Der Türken, 3(2), 99-111.

Creswell, J. W. (2012). Educational research: planning, conducting, and evaluating quantitative and qualitative research ( $4^{\text {th }}$. ed.). Boston: Pearson Education Inc.

Çetin Ş. Ö. (2014). Okul öncesi dönemindeki çocukların yazı farkındalığı ve yazmaya hazırlık becerilerinin incelenmesi. Kuramsal Eğitimbilim Dergisi, 7(3) 342-360.

Çerçi, A., \& Bardakçı, M. (2016). Yabancı dil olarak Türkçe öğrenen öğrencilerin yazılı anlatımlarına yönelik yanlış çözümlemesi. Gaziantep University Journal of Social Sciences, 15(2), 695-715.

Çevik, S. O. (2006). Birinci sınıf öğretmenlerinin ilkokuma yazma ögretiminde ses temelli cümle yöntemine ilişkin görüşleri (Bursa ili örneği), Unpublished master dissertation, Anadolu Üniversitesi Eğitim Bilimleri Enstitüsü, Eskişehir.

Dennis, J. L., \& Swinth, Y. (2001). Pencil grasp and children's handwriting legibility during different length writing tasks. American Journal of Occupational Therapy, 55, 175183.

Doğan, B. (2007). Denizli ili ilköğretim okullarında çalışan birinci sınıf öğretmenlerinin ses temelli cümle yöntemine ilişkin görüşleri. AİB̈̈ Eğitim Fakültesi Dergisi, 7(1),7990.

Dodd, B., \& Carr, A. (2003). Young children's letter-sound knowledge. Language, Speech and Hearing Services in Scholols, 34, 128-137.

Donoughue, C. (2009). Yazının öyküsü. İstanbul: Türkiye İş Bankası Yayınları.

Duran, E. (2011). Bitişik Eğik yazı harflerinin yazım şekillerine ilişkin öğretmen görüşleri. Ondokuz Mayıs Üniversitesi Eğitim Fakültesi Dergisi, 30(2), 55-69.

Duran, E., \& Akyol, H. (2010). Bitişik eğik yazı öğretimi çalışmalarının çeşitli değişkenler açısından incelenmesi. Türk Ĕ̈itim Bilimleri Dergisi, 8(4), 817-838.

Ellis H. (1992) Clinical anatomy, (pp. 207-215). London: Blackwell Scientific Publications,

Erdoğan, T. (2012). İlköğretim birinci sınıf öğrencilerinin bitişik eğik yazı yazma gelişimlerinin incelenmesi. Eğitim ve Bilim, 37(165), 2-11.

Erden, M., \& Akman, Y. (1998). Gelişim, öğrenme-öğretme. Ankara: Arkadaş Yayınları.

Erden T. F., \& Altun D. (2014). Sınıf öğretmenlerinin okul öncesi eğitim ve ilköğretime geçiş süreci hakkındaki görüşlerinin incelenmesi. İlköğretim Online, 13(2), 481-502.

Erdoğan, T. (2012). İlköğretim birinci sınıf öğrencilerinin bitişik eğik yazı yazma gelişimlerinin incelenmesi. Eğitim ve Bilim, 37(165) 93-103. 
Fatemeh, H., Hadi, B., Fatemeh, B., Mozhgan, F., \& Masood, S. (2008). Handwriting difficulties: Introducing an instrument, Iranian Rehabilitation Journal, 6(7-8), 39-46.

Feder, K. P., \& Majnemer, A. (2007). Handwriting development, competency and intervention, Developmental Medicine \& Child Neurology, 49(1), 312-317.

Fitzgerald, T. (2012). Documents and documentary analysis. In A. R. J. Briggs, M. Coleman., \& M. Morrison (Eds.), (pp. 296-308). Reseach methods in educational leadership and management. London: Sage.

Iş11, B. (1991). Ergonomi. İzmit: Yıldız Ün. Yayınları.

Graham, S., Harris K. R., Mason, L., Fink-Chorzempa, B., Moran, S., \& Saddler, B. (2008). How do primary grade teachers teach handwriting? A National Survey. Reading and Writing, 21(1-2),49-69.

Graham, S., Struck, M., Santoro, J., \& Bernınger, V. W. (2006). Dimensions of good and poor handwriting legibility in first and second graders: motor programs, visualspatial arrangement, and letter formation parameter setting. Developmental Neuropsychology, 29(1), 43-60.

Graham, S., Weintraub, N., Berninger, V.W., \& Schafer, W. (1998). Development of handwriting speed and legibility in grades 1-9. Journal of Educational Research, 92(1), 42-51.

Güler C. (2003). Ergonomiye giriş. Ankara: Ankara Tabip Odası.

Güneş, F. (2016). Türkçe öğretimi yaklaşımlar ve modeller. Ankara: Pegem Akademi.

Güneş, F. (2017). Bitişik eğik ve dik temel yazı savaşları. Sınırsız Eğitim ve Araştırma Dergisi, 2(3), 1-20.

Güneyli, A. (2006). Kitap incelemesi. İlköğretim Online, 5(2), 50.

Gürcan, S., \& Adıyaman S. (2008). Elin anatomisi ve kineziyolojisi. Türkiye Klinikleri. (El Rehabilitasyonu Özel Sayısı), 1(1),1-9.

Halıcı, B. (2019). Kalem şeklinin ilkokul öğrencilerinin yazma hızına etkisinin incelenmesi. (Yayınlanmamış yüksek lisans tezi). Yozgat Bozok Üniversitesi Sosyal Bilimler Enstitüsü, Yozgat.

Hamstra B. L., \& Blöte, W. A. (1993). A longitudinal study on dysgraphic handwriting in primary school. Journal of Learning Disabilities, 26(10), 689- 699.

Hamzadayı, E., \& Çetinkaya, G. (2011). Yazılı anlatımı düzenlemede akran dönütleri: dönüt türleri, öğrenci algıları. AIB̈Ü Ĕ̆itim Fakültesi Dergisi, 11(1), 147-165.

Havens M. C. (2002). Emergent writing in preschool. Unpublished doctoral dissertation, The State University of New Jersey, New Jersey. 
Höbek G., \& Taşkaya S. M. (2018). İlkokul öğrencilerinin yazma hızının belirlenmesi. Hitit Üniversitesi Sosyal Bilimler Enstitüsü Dergisi, 11(3), 2433-2445.

Kahraman G. (2001). Bilek, el ve parmakları hareket ettiren kas ve tendon yap1ları. El ve El bileği cerrahi anatomi mezuniyet sonrası ĕgitim kurs kitabı. İstanbul: Cerrahpaşa.

Karasar, N. (2013). Bilimsel araştırma yöntemi (25 ${ }^{\text {th }}$ ed.). Ankara: Nobel Yayın Dağıtım.

Kavak, S. T., \& Bumin, G. (2009). The effects of pencil grip posture and different desk design on handwriting performance in children with hemiplegic cerebral palsy. Journal de Pediatria, 85(4), 346-352.

Kırbaş, A., \& Orhan, S. (2011). Görsel materyallerle desteklenmiş yazma çalışmalarının öğrencilerin yazma becerilerini geliştirmeye etkisi. Turkish Studies, 6(4), 705-714.

Kırmızı, F. S., \& Ünal, E. (2016). İlk okuma yazma öğretimi. Ankara: Anı Yayıncılık.

Koziatek, S. M., \& Powell, N. J. (2003). Pencil grips, legibility and speed of fourth-graders' writing in cursive. American Journal of Occupational Therapy, 57(3), 284-288.

Lambert S. M. (2016). Shoulder girdle and arm. Section 6: Pectoral girdle and upper limb (ed. Rolfe Birch). Gray’s anatomy (41. Bask1), (ed. Susan Standring), (pp. 797-837). London: Elsevier,

Lubahn, J. D. (1996). Hand evaluation. Regional review courses in hand surgery (Courses Book). Portland, Oregon, 1-13.

MEB, (2006). Türkçe dersi öğretim programı. Ankara: MEB.

MEB, (2010). Türkçe dersi öğretim programı. Ankara: MEB.

MEB, (2015). Türkçe dersi öğretim programı. Ankara: MEB.

MEB, (2018). Türkçe dersi öğretim programı. Ankara: MEB.

MEB, (2019). Türkçe dersi öğretim programı. Ankara: MEB.

Medwell, J., \& Wray, D. (2007). Handwriting: what do we know and what do we need to know? Literacy, 41(1), 10-15.

Memiş, A. D., \& Harmankaya, T. (2012). İlköğretim okulu 1. sınıf öğrencilerinin bitişik eğik el yazısı hataları ile görsel alg1 düzeylerinin incelenmesi. Dicle Üniversitesi Ziya Gökalp Ĕ̈itim Fakültesi Dergisi, 19,136-150.

Overvelde, A., \& Hulstijn, W. (2011). Handwriting development in grade 2 and 3 primary school children with normal, at risk, or dsygraphic characteristics. Research in Developmental Disabilities, 32(1), 540-548.

Palmis, S., Velay, J. L., Danna, J., \& Longcamp, M. (2017). Motor control of handwriting in the developing brain: A review. Cognitive Neuropsychology 34(27), 1-18. 
Phelps, J., Stempel, L., \& Speck, G. (1985). The Children's handwriting scale: A new diagnostic tool. Journal of Educational Research,79(1), 46-50.

Power, B. M., \& Hubbard, R. S. (1996). Language development a reader for teachers. New Jersey: Prentice Hall Inc.

Ross, A. C. (2016). Wrist and hand. Pectoral girdle and upper limb (ed. Rolfe Birch). Gray's anatomy (41th. Ed.), (eds. Susan Standring), (pp. 862-877). London: Elsevier.

Schneck, C. M. (1991). Comparison of pencil-grip patterns in first graders with good and poor writing skills. The American Journal of Occupational Therapy, 45(8), 701-706.

Schneck, C. M., \& Henderson, A. (1990). Descriptive analysis of the developmental progression of grip position for pencil and crayon control in no dysfunctional children. The American Journal of Occupational Therapy, 44(10), 893-900.

Summers, J., \& Catarro, F. (2003). Assessment of handwriting speed and factors influencing written output of universitiy students in examinations. Australian Occupational Therapy Journal, 50, 148-157.

Tashakkori, A., \& Teddlie, C. (Eds). (2003). Handbook of mixed methods in social and behavioral research. Thousand Oaks, CA: Sage.

Taylor, J. (2006). Developing handwriting skills. Stackhouse, J. (Eds.) A practitioner's handbook. Dislexia. Speech and language (2nd Edition), (229-252). London: Whurr Publishers

Taylor, J. S. (2010). Supervision and teaching of handwriting. U.K.: Lightning source.

Tok, R., \& Erdoğan, Ö. (2017) İlkokul 2. 3. ve 4. sınıf öğrencilerinin yazma becerilerinin incelenmesi. YYÜ Ĕgitim Fakültesi Dergisi, 14(1), 1003-1024.

Tseng, M. H. (1998). Development of pencil grip position in preschool children. Occupational Therapy Journal of Research, 18, 207-224.

Tseng, M. H., \& Cermak S. A. (1993) The influence of ergonomic factors and perceptualmotor abilities on handwriting performance. American Journal of Occupational Therapy, 47(10), 919-926.

Uysal I. I. (2003). Nervus medianus'un klinik anatomisi ve varyasyonları. Genel Tip Dergisi, 13(2), 89-93.

Valantin P. (1981). Physiology of extension of the fingers. The hand. (Eds. Tubiana, R.) (pp. 389-98). Philadelphia: Saunders.

Vlachos, F., \& Bonoti, F. (2006). Explaining age and sex differences in children's handwriting: a neurobiological approach. European Journal of Developmental Psychology, 3(2), 113-123. 
Yıldırım, A., \& Şimşek, H. (2003). Sosyal bilimlerde nitel araştırma yöntemleri. Ankara: Seçkin Yayıncılık.

Yıldız, M., Açan, M., Berber, V., Bulut, S., \& Zalimhan, R. (2015). İlkokul öğrencilerinin yazma sürecindeki ergonomik tercihleri: tutma, el tercihi, oturuş ve kâğıt pozisyonu. International Journal of Social Science, 40, 61-71.

Yıılız, M., Yıldırım, K., \& Ateş, S. (2009). Sınıf öğretmenlerinin sınıf tahtasına yazdıkları yazıların okunaklılık bakımından öğrencilere model olmadaki uygunluğu. Uluslararası İnsan Bilimleri Dergisi, 6(2), 75-88.

Yılmaz, A., \& McMullan, M. B. (2010). Head start sınıflarında erken okuma-yazma müfredatını geliştirmeye yönelik bir çalışma. Eğitim ve Bilim, 35(158) 169-183.

Yücebaş, Ç. (2006). Grafik tasarımda görsel bütünlük oluşturmada tipografi ile görseller arasındaki ilişki ve sanat eğitimindeki yeri, Unpublished doctoral dissertation, Dokuz Eylül Üniversitesi Eğitim Bilimleri Enstitüsü, İzmir.

Warwick, A. (2003). Nelson handwriting: Resources and assessment. U. K.: Nelson Thornes.

http://alfabesi.com/fenike-alfabesi on 19 October 2019

http://researchgate.net/figure/Movement-description-a-Shoulder-flexion-bElevation-inscapula-plane_fig3_318640138 on 21 November 2019

http://wfnk.com/2014/09/wrist-input-is-just-starting on 21 November 2019

http://kenhub.com/en/library/anatomy/the-superficial-flexors-of-the-forearm on

November 2019

http://kenhub.com/en/library/anatomy/radial-muscles-of-the-forearm on 15 November 2019 http://anatomyinfo.com/hand-muscles on 15 November 2019

http://zipfslaw.org/2018/08/12/motor-homunculus on 15 November 2019

http://musicalbrainwaves.weebly.com/motor-cortex.html on 15 November 2019 